\title{
ENTREPRENEURIAL SPAWNING AND FIRM CHARACTERISTICS *
}

\author{
Michel A. Habib ${ }^{\dagger} \quad$ Ulrich Hege $e^{\ddagger} \quad$ Pierre Mella-Barral ${ }^{\S}$
}

May 2011 ฯ

\begin{abstract}
We analyze the implications of entrepreneurial spawning for a variety of firm characteristics such as size, focus, profitability, and innovativeness. We examine the dynamics of spawning over time. Our model accounts for much of the empirical evidence relating to the relation between spawning and firm characteristics. Firms that have higher patent quality spawn more, as do firms that have higher knowhow. Older firms spawn less, they are more diversified and less profitable. Spawning frequency, focus, and profitability are positively related where spawning is driven by the value of organizational fit; they are negatively related with firm size.
\end{abstract}

JEL classification: L25, M13, O31, O33.

Keywords: innovation incentives, spawning, spinouts, organizational fit, firm size, firm focus, firm dynamics, spawning and diversifying entry.

\footnotetext{
${ }^{*}$ The authors gratefully acknowledge financial support from the European Commission, Ricafe2 Project (Contract CIT5-CT-2006-028942) and from the National Centre of Competence in Research, Financial Valuation and Risk Management (NCCR FINRISK).

${ }^{\dagger}$ Swiss Finance Institute, University of Zurich, Plattenstrasse 14, 8032 Zurich, Switzerland; tel.: +41 (0)44-6342507; e-mail: habib@isb.unizh.ch; CEPR.

${ }^{\ddagger}$ HEC School of Management Paris, Department of Finance and Economics, F-78351 Jouy-en-Josas Cedex, France; Tel. +33 (0)1-3967-7299; e-mail: hege@hec.fr.

${ }^{\S}$ EDHEC Business School, 393 promenade des Anglais, F-06202 Nice Cedex 3, France; tel.: +33 (0)4-9318-7841; e-mail: mella@edhec.edu.

"We would like to thank Engelbert Dockner, Claudio Loderer, and seminar participants at ESSEC Paris, NHH Bergen, the universities of Bern, Konstanz, Lausanne, Paris-Dauphine, Pompeo Fabra Barcelona, Besancon and the CEPR conference "Corporate Finance and Economic Performance" at the University of St. Gallen for helpful comments and discussions. We are responsible for all errors.
} 


\section{Introduction}

Entrepreneurial spawning - the process whereby an existing firm gives birth to a new firm set up by one or more employees departed from the existing firm - is prevalent in many new industries. It is well-known, for example, that Fairchild Semiconductors has been the forebear of a great many Silicon Valley semiconductor firms, the "mother hen of the Northern California semiconductor industry" (Rogers, 1985, p. 24). In his history of the genesis of Silicon Valley, Hall (1998, p. 437) writes "about half of the eighty-five or so US semiconductor companies of the 1980s were direct spin-offs from the firm." ${ }^{1}$ It is perhaps less well-known that similar statements can be made about many industries: disk drives (Agarwal, Echambadi, Franco, and Sarkar, 2004; Christensen, 1993; Franco and Filson, 2006), lasers (Klepper and Sleeper, 2005; Sherer, 2006), tires (Buenstorf and Klepper, 2009), and automobiles (Klepper, 2007).

The phenomenon of entrepreneurial spawning — also referred to as spinning off or spinning outhas been quite extensively studied. Less studied have been the implications of spawning for a variety of firm characteristics such as size, focus, profitability, and innovativeness. We believe that a better understanding of these implications can contribute towards a better understanding of the nature of the firm. Gompers, Lerner, and Scharfstein (2005) have studied empirically the relation of spawning with firm characteristics. The present paper develops a model that does so theoretically. Its results generally coincide with Gompers, Lerner, and Scharsftein's findings. The paper also examines the dynamics of spawning over time and their implications for the evolution of firm characteristics. Finally, the paper examines the extent and the profitability of entry by spawning: it computes the number of spawned entrants into a new industry and compares the profitability of entry by spawned firms with diversifying entry by firms active in other industries.

As our results revolve around the nature and the extent of spawning, it is natural to ask what determines spawning: why should an employee that has developed a new product start a new firm rather than remain in his current employment? We motivate spawning by the desire to achieve organizational fit, that is, the fit between a firm's organization and the requirements for the successful management of the firm's product portfolio. ${ }^{2}$ In our model, spawning occurs where the employee who developed the new product finds it beneficial to start a new firm to commercialize

\footnotetext{
${ }^{1}$ Hall (1998) cites Hanson (1982, p. 110) who observes that "[[t]hroughout the sixties, bright young engineers spun out of Fairchild like so many enterprizing Minervas from the head of Zeus. New start-ups abounded: three new chip makers in 1966, another three in 1967, thirteen in 1968, eight more in 1969; their names a seemingly endless set of permutations on a few basic syllables - tech, tronic, inter, micro, ics, tron, etc."

${ }^{2}$ Roberts (2004, p.11) writes that "there needs to be a fit between strategy and organization and between these and the technological, legal, and competitive environment."
} 
that product, because the product presents little fit with the organizational form of the firm at which the employee originally is employed. The employee bargains with the firm over the term of his departure. The benefit of spawning is the choice of an organizational form better suited to the new product; its cost that of setting up the new firm. There is a threshold organizational fit: products whose fit with firm organization exceeds the threshold are retained within the original firm, those whose fit does not are spawned to new firms.

Spawning naturally has consequences for firm characteristics. Ceteris paribus, a firm that spawns more grows more slowly: products that otherwise would be retained within the firm are spawned to new firms. Spawning increases firm focus: as it is lesser fitting products that are spawned to new firms, a greater extent of spawning increases the average fit of those products retained within the firm, that is, it increases firm focus. As focus improves profitability, ceteris paribus, spawning increases firm profitability, too. Finally, spawning increases a firm's investment in innovation: a product spawned generally is more profitable, because it is sold by a new firm with form of organization better fitting the product. Greater product profitability increases the incentive to invest in innovation. This last result underlines the importance of the ceteris paribus qualification: larger incentives to innovate will lead to a greater number of new products that may increase firm size, despite the spawning of a larger fraction of these products; the relation between spawning and firm size is therefore ambiguous.

In order to study the dynamics of spawning over time and its implications for the evolution of firm characteristics, we introduce the - hitherto unnecessary - assumption that the cost of setting up a new firm increases over time: as a new industry develops and firms active in the industry acquire new knowledge through learning-by-doing for example, it becomes costlier for new firms seeking to enter the industry to acquire or replicate the body of knowledge these firms would need in order successfully to operate in the industry. The frequency of spawning therefore decreases over time. The decline in spawning naturally has implications for size, which grows over time; for focus, which decreases; for profitability, which decreases; and for innovativeness, which decreases.

As spawning constitutes the exclusive cause of new firm creation in our model, the decline in spawning implies a decline in the rate of new firm creation. The number of new firms may however increase in the early stages of an industry, as the decline in the rate of new firm creation is offset by the larger number of firms from which new firms are spawned. The former eventually dominates, at which point the number of new firms declines.

We compare entry by spawning and diversifying entry, that is entry by firms active in other industries. Laux's (1976) study of the early automobile industry in France reveals that many at- 
tempts at car manufacturing were undertaken by existing bicycle and coach manufacturers. Klepper's (2002) study of the industry in and around Detroit finds that spawned firms - firms founded by individuals previously employed by existing car manufacturers - performed at least as well as diversifying firms. Klepper and Thompson (2009) provide a disagreements-based theoretical rationale for this finding. We revisit this issue in the context of our model. We show that diversifying firms have lower value of fit than spawned firms; diversifying entry is therefore less profitable than entry by spawning, unless diversifying firms have markedly higher value of skills than their spawned counterparts. This is consistent with the view that it is firms with less specific, more general resources that choose to diversify (Bernardo and Chowdhry, 2002; Matsusaka, 2001).

We view our model as pertaining primarily to new firms in the early stages of a new industry. This is reflected in the assumptions that we make. We assume a firm is owned by the individuals that constitute the firm's human capital, the scientists, engineers, and other technical and nontechnical personnel that devise various innovations and choose whether to have these retained within the firm or spawned to a new firm. We further assume that a new firm spawned from an existing firm has access to the same 'innovation technology' as does the existing, spawning firm. This assumption-true in the early stages in a new industry, as when Intel was spawned from Fairchild in 1968 - has the important benefit of imparting no built-in advantage or disadvantage to firm size. In our model, a larger firm innovates more or less than its smaller counterpart not because of some inherent property of large or small firms, but because the underlying parameters that make firms larger or smaller also make them more or less innovative.

Many of our predictions appear to be consistent with the available empirical evidence: firms that have higher patent quality and younger firms spawn more (Gompers, Lerner, and Scharfstein, 2005), as do firms that have higher knowhow (Franco and Filson, 2006). All of our predictions are induced by spawning, but some extend beyond spawning: older firms are also more diversified (Denis, Denis, and Sarin, 1997) and less profitable (Loderer and Waelchli, 2009). Some of our predictions are new and may help shed new light on issues perhaps still controversial. Consider for example the spawning-induced relation between focus and profitability. Our work suggests that these two endogenous firm characteristics are positively related where the relation is driven by the value of organizational fit; they may be negatively related where the relation is driven by the value of firm skills. This may account for the somewhat mixed evidence regarding the relation between focus/diversification and performance/value. ${ }^{3}$ Our model is also able to account for the finding

\footnotetext{
${ }^{3}$ There is an extensive literature on the relation between diversification and performance, starting with the seminal work of Berger and Ofek (1995) and Lang and Stulz (1994). See for example Campa and Kedia (2002); Graham, Lemmon, and Wolf (2002); Schoar (2002); Villalonga (2004); and Whited (2001).
} 
by Loderer and Waelchli (2009) that firms become less profitable as they mature. Our analysis attributes this finding, which is difficult to reconcile with the view of firm growth as being driven by increased firm resources, skills, and/or knowhow (Klette and Kortum, 2004; Penrose, 1995), to the decline in spawning, thereby focus, over time.

The paper proceeds as follows. Section 2 reviews the literature. Section 3 presents the model. Section 4 solves the model for firm value and the extent of spawning. Section 5 examines the firm characteristics of interest and derives their comparative statics. Section 6 examines the dynamics of spawning over time and their implications for the evolution of firm characteristics. Section 7 examines the extent of entry by spawning and compares the profitability of spawning entry with that of diversifying entry. Section 8 provides supporting empirical evidence and derives a number of testable implications. Finally, Section 9 concludes.

\section{Literature Review}

Our work is related to various strands of the literature. It is of course related to the literature on spawning, which has sought to explain when an innovation is retained to be implemented 'inhouse' and when it is spawned to a new firm. ${ }^{4}$ It is also related to the literature on firm size and firm growth, that part of the literature in particular that has attributed a firm's growth to the firm's entry into new submarkets (Klepper and Thompson, 2006; Klette and Kortum, 2004; Sutton, 1998): our products are these papers' submarkets. ${ }^{5}$ Finally, it is related to the literature on firm focus and diversification, in particular that part of the literature which has sought to explain why diversification might create value despite being associated with lower average firm value and performance. $^{6}$

Where previous work has examined each of the issues mentioned above in much detail, our work attempts to tie these together in one single model which, as noted above, accounts for firm size, performance, focus, and innovativeness, and for the extent of spawning by the firm. What ties these together is organizational fit: fit i) determines individual product profitability, therefore determining the incentive to invest in the development of new products, i.e., innovativeness, ii) determines

\footnotetext{
${ }^{4}$ See for example Amador and Landier (2002); Anton and Yao (1995); De Bettignies and Chemla (2008), Cassiman and Ueda (2006); Franco and Filson (2006); Gromb and Scharfstein (2002); Hellmann (2007); and Klepper and Thompson (2009).

${ }^{5}$ There is a large literature on firm size and firm growth that is surveyed in Sutton (1997) and Coad (2009).

${ }^{6}$ See for example Bernardo and Chowdhry (2002); Gomes and Livdan (2004); Maksimovic and Phillips (2002); Matsusaka (2001); and Matsusaka and Nanda (2002).
} 
the products the firm introduces itself and those the firm leaves to the firms it spawns, thereby determining size, and iii) determines overall firm profitability through focus, that is, average organizational fit. Our focus on organizational fit i) accounts for the decision to spawn without appealing to additional considerations such as contractual flexibility, intellectual property rights, multi-task agency, the distinction between innovation and imitation, or disagreements and ii) accounts for product diversification without the need for internal capital markets, winner-picking skills, or decreasing returns to scale. ${ }^{7}$ We do not doubt the importance of these and other considerations, but believe there is a value to a common explanation with a single consideration. ${ }^{8}$

Our paper is closest to Cassiman and Ueda (2006) and to Gompers, Lerner, and Scharfstein (2005). We follow Cassiman and Ueda in stressing the importance and exploring the implications of organizational fit. Where Cassiman and Ueda examine the process of spawning in great detail, we explore its implications for firm characteristics and for rate and form of entry. We follow Gompers, Lerner, and Scharfstein in examining the relation between spawning and firm characteristics. Where their analysis is empirical, ours is theoretical.

Klepper and Thompson (2009, p. 12) take issue with organizational fit-based rationales for spawning such as ours, based on incumbents' "limited ability or capacity to manage diverse projects." They view these explanations as being contradicted by the observations that i) most of the disagreements they report were central to spawning firms' missions and ii) better performing firms spawned more; the firms they spawned in turn performed better. We note that there need be no contradiction between limited ability or capacity and centrality once one recognizes that organizational fit applies as much to market or process as to product..$^{9}$ Consider for example Christensen's

\footnotetext{
${ }^{7}$ Regarding i), Amador and Landier (2002) induce spawning by attributing greater contractual flexibility to external, venture capital financing than to internal financing; Anton and Yao (1995) and Hellmann (2007) make the decision to spawn revolve around the allocation of intellectual property rights and, in the case of Hellmann, the need to induce an employee to exert effort on a core task where the employee might otherwise be tempted to exert effort on another, innovative task; Franco and Filson (2006) limit innovation to firms and employees to imitation; they induce spawning by requiring that an employee who wishes to innovate start his own firm; Klepper and Thompson (2009) attribute the decision to spawn to disagreements between employer and employee. Regarding ii), Fluck and Lynch (1999), Gertner, Scharfstein, and Stein (1994), Matsusaka and Nanda (2002), and Rajan, Servaes, and Zingales (2000) study internal capital markets in conglomerates; Stein (1997) studies winner-picking skills; Gomes and Livdan (2004) and Maksimovic and Phillips (2002) study decreasing returns to scale.

${ }^{8}$ We follow Bernardo and Chowdhry (2002) and Matsusaka (2001) in introducing a distinction between general and specific resources; such distinction does not, however, play as central a role in prompting diversification in our work as in theirs: diversification would occur in our model even absent general resources.

${ }^{9}$ This is not to dispute the importance of disagreements - or of mere corporate inertia - as a motivation for spawning.
} 
(1997) finding, reported by Cassiman and Ueda (2006, p. 271), that "two-thirds of the spin-offs in the hard disk drive industry entered new submarkets, which did not fit the established firms' existing customer base." An established hard disk drive manufacturer that had been presented the opportunity to develop a new disk drive for a new market segment might quite reasonably have concluded that it did not have the ability or capacity to service the new segment, despite disk drives being central to the manufacturer's mission. We establish the greater extent of spawning by better performing firms and the better performance spawned firms in Sections 5 and 7; we discuss these in Section 8.

\section{The Model}

\subsection{The Firm}

Consider a firm $f$ set up in a period $t_{f}$ at a cost $\kappa_{t_{f}} \in \mathbb{R}^{+}$. Firm $f$ has three characteristics that are central to our analysis: its organizational form, its portfolio of products, and its human capital.

- The firm's organizational form, $m_{f}$, is represented by a point on the real line, $\mathbb{R}$; the firm chooses its form of organization upon set up; organizational imprint and structural inertia (Carroll and Hannan, 2000; Jovanovic and Rousseau, 2001) combine to make that choice irreversible.

- The firm is born with a single product, $\theta_{f} \in \mathbb{R}$ for firm $f$. Innovations provide the firm with the opportunity to introduce new products; these too are represented by points on the real line. We denote by $\mathcal{I}_{f t}$ the portfolio of products of firm $f$ in period $t ; \mathcal{I}_{f t}$ represents the products introduced by the firm between periods $t_{f}$ and $t$. We let $I_{f t} \equiv\left|\mathcal{I}_{f t}\right|$ denote the number of products in $\mathcal{I}_{f t}$.

- The firm's human capital, $\mathcal{A}$, consists of the set of agents who own the firm, devise the firm's innovations, and choose whether to have these retained within the firm or spawned to a new firm (see Section 3.2 below). ${ }^{10}$ We assume agents are homogeneous; we let $A \equiv|\mathcal{A}|$ denote the number of agents in $\mathcal{A} ; A$ is assumed constant over time. ${ }^{11}$ At the start of period $t>t_{f}$,

\footnotetext{
${ }^{10}$ It is perhaps most natural to think of these agents as the scientists, engineers, and other key technical and nontechnical personnel who founded the firm or joined it soon afterwards, develop and market its products, and make its main decisions. The firm may employ other personnel such as clerical and production workers, but these need not be modeled explicitly as they generally have little ownership in the firm and neither devise innovations nor affect the decision whether to retain or to spawn.

${ }^{11}$ The number of agents, $A$, may be considered the result of some unmodeled optimization.
} 
every agent $a \in \mathcal{A}$ attempts to devise an innovation. The agent chooses a probability $q_{t}$ at a cost to the agent $c\left(q_{t}\right) ; q_{t}$ is the probability that the agent is successful at devising an innovation. We consider a symmetric equilibrium for simplicity. We assume

$$
c\left(q_{t}\right)=\frac{\zeta}{2} q_{t}^{2}
$$

The parameter $\zeta \in \mathbb{R}^{+}$measures the difficulty of innovation. The probabilities $q_{t}$ are assumed independent across agents and time. ${ }^{12}$

An innovation provides the firm with the opportunity to introduce a new product, $\theta_{i} \in \mathbb{R}$. We assume $\theta_{i}$ is uniformly distributed over an interval of length $2 \delta$ centered at firm $f$ 's organizational form, $m_{f}: \theta_{i} \sim U\left[m_{f}-\delta, m_{f}+\delta\right]$ : organizational form determines the range of possible innovations.

We define organizational fit $\omega_{i} \in(0,1)$ to be the complement of the normalized distance between organizational form $m_{f}$ and product $\theta_{i}: \omega_{i} \equiv 1-\left|\frac{\theta_{i}-m_{f}}{\delta}\right|$. The fit is maximal $\left(\omega_{i}=1\right)$ where the new product coincides with organizational form, $\theta_{i}=m_{f}$; it is minimal $\left(\omega_{i}=0\right)$ where the new product is most peripheral, $\theta_{i}=m_{f} \pm \delta$.

Organizational fit, the fit between the product and the firm's organizational form, combines with firm skills to determine the per-period profit to firm $f$ from selling product $\theta_{i}$. Specifically,

$$
\pi_{i}=\alpha+\beta \omega_{i}
$$

The parameter $\alpha$ measures the value of firm skills. The parameter $\beta$ measures the value of organizational fit, $\omega_{i}$ : the larger $\beta$, the greater the profit $\beta \omega_{i}$ attributable to organizational fit. Note that profit would be zero if fit were zero $\left(\omega_{i}=0\right)$, however large $\beta$ might be. Thus, $\beta$ may to some extent be considered a measure of the value of product- or industry-specific resources, $\alpha$ that of general resources. ${ }^{13}$ Both $\alpha$ and $\beta$ are assumed to be constant over time; per-period profit $\pi_{i}$ from selling product $\theta_{i}$ is therefore constant over time. ${ }^{14}$

Note that firm $f$ 's optimal organizational form, $m_{f}^{*}$, equals $\theta_{f}$. This is immediate from the symmetry of both the profit function and the distribution of innovations: both are functions of $\left|\theta_{f}-m_{f}\right|$. Firm $f$ in period $t_{f}$ therefore sets $m_{f}=\theta_{f}$.

\footnotetext{
${ }^{12}$ There is neither cooperation nor competition among agents; this assumption is made for simplicity.

${ }^{13}$ We borrow the term 'resources' from the Resource-Based View of the firm (Penrose, 1995; Wernerfelt, 1984).

${ }^{14}$ Such can be the case even as firm skills increase over time where markets are contestable. Briefly, contestability requires the firm to pass the benefits of increased skills onto consumers in the form of lower prices; per-period profit remains constant over time.
} 


\subsection{Spawning and Firm Creation}

The innovating firm $f$ need not introduce all new products itself. A new product born of an agent's innovation may be more efficiently introduced by a new firm started by the agent who devised the innovation. We refer to such an outcome as 'entrepreneurial spawning:' the agent who devised the innovation becomes an entrepreneur who starts a new firm; the new firm is spawned from the innovating firm. Let $f^{+}$denote the firm spawned from firm $f$. Firm $f^{+}$is assumed to inherit firm $f$ 's values of skills $(\alpha)$ and fit $(\beta) .{ }^{15}$ The advantage of leaving the introduction of a new product such as $\theta_{i}$ to the new firm is that the firm can have organizational form, $m_{f^{+}}$, perfectly fitting the product: $m_{f^{+}}=\theta_{i}{ }^{16}$ This increases the profits from selling the new product from $\alpha+\beta \omega_{i}$ to $\alpha+\beta .{ }^{17}$ It does, however, involve a cost, $\kappa_{t}$, of setting up the new firm. We allow set-up costs to vary over time; we make specific assumptions about $\kappa_{t}$ 's time-variation in Sections 6 and 7.1. ${ }^{18}$

There is a trade-off between organizational fit and set-up cost, the former favoring spawning, the latter retention. This trade-off leads to the existence of a threshold fit $\omega_{t}^{*}$ such that the introduction of the new product is left to the spawned firm where $\omega_{i} \in\left(0 ; \omega_{t}^{*}\right)$ and to the innovating firm where $\omega_{i} \in\left[\omega_{t}^{*} ; 1\right]$ : a firm spawns those products that present a lesser fit with the firm's organizational form. We derive the expression for $\omega_{t}^{*}$ in Section 4 below. We assume that $\kappa_{t}<\frac{\beta}{\rho}$ for all $t \geq t_{f}$ : this ensures there is spawning.

Where an agent $a \in \mathcal{A}$ has devised an innovation $\theta_{i}$, agent $a$ bargains with his fellow agents in $\mathcal{A}$ over the value of that innovation. We assume costless bargaining and denote by $\gamma, 0 \leq \gamma \leq 1$, the bargaining power of agent $a$ who devised the innovation. We invoke the generalized Nash bargaining solution to conclude that agent $a$ receives a fraction $\gamma$ of the value of the innovation he has devised. ${ }^{19}$ The remaining fraction, $1-\gamma$, is shared by the other agents, $\mathcal{A} \backslash\{a\}$. No other party partakes in the bargaining process: decision power within the firm belongs to those who own and

\footnotetext{
${ }^{15}$ Agarwal, Echambadi, Franco, and Sarkar (2004) provide strong evidence of inheritance by spawned from spawning firms.

${ }^{16}$ We assume that imprinting and inertia (Carroll and Hannan, 2000; Jovanovic and Rousseau, 2001) constrain the innovating firm's organizational form to remain fixed at the original $m_{f}=\theta_{f}$. The firm neither can alter its original organizational form nor can it set up a new division with divisional organizational form different from the original form. We therefore exclude the possibility for the innovating firm to set up a new division with divisional organizational form $\theta_{i}$ to introduce the new product.

${ }^{17} \mathrm{We}$ assume that the new product always is introduced and that it does not cannibalize existing products. These assumptions are made for simplicity; they do not alter the nature of our results.

${ }^{18}$ Our results would have been similar had we instead allowed the value of fit, $\beta$, to vary over time; the value of skills, $\alpha$, will be seen below to have no bearing on the decision to spawn.

${ }^{19}$ Bargaining power is to a large extent determined by intellectual property rights: $\gamma$ is large where intellectual property rights are weak and innovators appropriate much of the value of their innovations.
} 
operate the firm.

In case there should be spawning and agent $a$ start a new firm, $f^{+}$, agent $a$ likely will devise other innovations, as will other agents that may join $a$ in $f^{+} .{ }^{20}$ In order to maintain the centrality of organizational fit to our analysis and to avoid imparting any built-in advantage - organizational fit excepted - to either spawning firm or spawned firm, we assume that both the spawning firm, $f$, and the spawned firm, $f^{+}$, have access to the same 'innovation technology.' In the context of our model and given the assumed homogeneity of agents, the assumption of identical 'innovation technology' implies that firm $f^{+}$has i) human capital $\mathcal{A}^{+}$such that $\left|\mathcal{A}^{+}\right|=|\mathcal{A}|=A$ and ii) cost of innovation $c\left(q_{t}\right)$ per agent in $\mathcal{A}^{+}$. Thus, firm $f$ replaces agent $a$ by another agent; agent $a$ has $A-1$ agents join him in constituting firm $f^{+}$'s human capital.

As spawning occurs, new firms are born; other firms die. We assume that a firm in existence at the beginning of period $t$ has probability $\lambda$ of dying during that period; more formally, we assume that firm exit follows a Poisson process with exit rate $\lambda \in \mathbb{R}^{+}$per period. The effective discount rate, $\rho \equiv r+\lambda$, therefore combines the discount rate $r \in \mathbb{R}^{+}$and the exit rate $\lambda$. We denote by $\mathcal{F}_{t}$ the set of firms in existence at the beginning of period $t$ and by $F_{t} \equiv\left|\mathcal{F}_{t}\right|$ the number of firms in $\mathcal{F}_{t}$.

We represent the sequence of events on the time-line in Figure 1. We divide period $t$ into two subperiods, starting at dates $t$ and $t+\epsilon$, respectively. At date $t$, each of the $A$ agents of firm $f$ invests $c\left(q_{t}\right)$. At date $t+\epsilon$, agent $a \in \mathcal{A}$ devises an innovation $\theta_{i}$ with probability $q_{t}$. Agent $a$ bargains with his fellow agents; the innovation is retained or is spawned. In the latter case, agent $a$ departs to start a new firm, $f^{+}$; agent $a$ is replaced by a new agent in $f$; he is joined by $A-1$ agents in $f^{+}$.

\section{Solving the Model}

Our purpose in the present section is to determine an agent's probability of innovation, $q_{t}$, and the threshold fit, $\omega_{t}^{*}$. For that purpose, we need to determine the expected value of the innovations agents will devise, for an individual agent and for all agents.

Consider an innovation $\theta_{i}$ devised by an agent $a, a \in \mathcal{A}$, at date $t+\epsilon$. Denote by $v_{t+\epsilon}^{\text {in }}\left(\omega_{i}\right)$ the value of the innovation if retained within the firm at date $t+\epsilon$ and by $v_{t+\epsilon}^{\text {out }}$ if spawned to a

\footnotetext{
${ }^{20}$ We assume agent $a$ 's former colleagues in firm $f, \mathcal{A} \backslash\{a\}$, have no claim whatsoever on firm $f^{+}$'s other innovations. It is possible to relax this assumption, along with the assumption that a firm belongs to the individuals that constitute its human capital; the greatly increased complexity yields relatively few benefits in added insights.
} 
new firm. Note the dependence of $v_{t+\epsilon}^{\text {in }}$ but not $v_{t+\epsilon}^{\text {out }}$ on $\omega_{i}$, a natural consequence of the choice of organizational form perfectly fitting $\theta_{i}$ in the new firm. Recalling that spawning involves set-up costs $\kappa_{t}$, we have

$$
v_{t+\epsilon}^{i n}\left(\omega_{i}\right)=\sum_{\tau=1}^{\infty} \frac{\alpha+\beta \omega_{i}}{(1+\rho)^{\tau}}=\frac{\alpha+\beta \omega_{i}}{\rho},
$$

and

$$
v_{t+\epsilon}^{\text {out }}=\sum_{\tau=1}^{\infty} \frac{\alpha+\beta}{(1+\rho)^{\tau}}-\kappa_{t}=\frac{\alpha+\beta}{\rho}-\kappa_{t} .
$$

The expected value at date $t$ of an innovation successfully devised at date $t+\epsilon$ is

$$
v_{t} \equiv \int_{0}^{\omega_{t}^{*}} v_{t+\epsilon}^{\text {out }} d \omega_{i}+\int_{\omega_{t}^{*}}^{1} v_{t+\epsilon}^{\text {in }}\left(\omega_{i}\right) d \omega_{i},
$$

where $\omega_{t}^{*}$ remains to be determined. As an innovation is devised successfully with probability $q_{t}$, the expected value of an innovation before success at devising the innovation can be ascertained is $q_{t} v_{t}$.

Agent $a$, the innovator, receives a fraction $\gamma$ of the value of the innovation, $v_{t}$. Denote $x_{t} \equiv \gamma v_{t}$ the agent's share of a successful innovation. From the point of view of agent $a$, the costly choice of an innovation probability $q_{t}$ earns $q_{t} x_{t}$ in expectation. Agent $a$ 's expected payoff from innovation is not limited to $q_{t} x_{t}$, however: agent $a$ profits through bargaining from the innovations devised by his fellow agents. ${ }^{21}$ Using the homogeneity of agents, the symmetry of the equilibrium, and the independence of innovation probabilities across agents and denoting $q_{t}^{\prime}$ the probability of innovation by each of $a$ 's fellow agents, the expected value at date $t$, to agent $a$, of all innovations devised at date $t+\epsilon$ is

$$
q_{t} x_{t}+(A-1) q_{t}^{\prime} \frac{v_{t}-x_{t}}{A-1}=q_{t} x_{t}+q_{t}^{\prime}\left(v_{t}-x_{t}\right) .
$$

The second term on the LHS represents $a$ 's expected payoff from the innovations devised by his $A-1$ fellow agents: there are $(A-1) q_{t}^{\prime}$ such innovations in expectation; each innovation has total value $v_{t}-x_{t}$ to those $A-1$ agents who did not devise the innovation; that value is divided equally among these $A-1$ homogenous agents. The distinction between $q_{t}$ and $q_{t}^{\prime}$ reflects agent $a$ 's non-cooperative behavior in choosing innovation probabilities.

Extending to all dates, the expected value at date $t$, to agent $a$, of all future innovations is therefore

$$
V_{t}^{a} \equiv \max _{q_{t}}\left\{-c\left(q_{t}\right)+q_{t} x_{t}+q_{t}^{\prime}\left(v_{t}-x_{t}\right)+\frac{V_{t+1}^{a}}{1+\rho}\right\}
$$

\footnotetext{
${ }^{21}$ Conversely, $a$ 's fellow agents profit through bargaining from the innovations devised by $a$.
} 
Observing that $q_{t}$ and $q_{t}^{\prime}$ do not affect $V_{t+1}^{a}$ as innovation probabilities are independent across time, using Equation (1), and maximizing, we have

$$
q_{t}=\frac{x_{t}}{\zeta}
$$

Using the symmetry of the equilibrium to write $q_{t}^{\prime}=q_{t}$ and therefore $q_{t} x_{t}+q_{t}^{\prime}\left(v_{t}-x_{t}\right)=q_{t} v_{t}$ and summing over all $A$ agents, we obtain the expected value at date $t$, to all agents, of all future innovations

$$
\begin{aligned}
V_{t}^{\mathcal{A}} & \equiv \Sigma_{a \in \mathcal{A}} V_{t}^{a}=\Sigma_{a \in \mathcal{A}}\left(-c\left(q_{t}\right)+q_{t} v_{t}+\frac{V_{t+1}^{a}}{1+\rho}\right) \\
& =-A c\left(q_{t}\right)+p_{t} v_{t}+\frac{V_{t+1}^{\mathcal{A}}}{1+\rho},
\end{aligned}
$$

where

$$
p_{t} \equiv A q_{t}=A \frac{x_{t}}{\zeta}=\frac{x_{t}}{\xi}
$$

denotes the date- $t$ expected number of innovations devised at date $t+\epsilon$ by all $A$ agents of the firm; $\xi \equiv \zeta / A$. We refer to $p_{t}$ as the frequency of innovation.

We are now in a position to determine the threshold fit, $\omega_{t}^{*}$, defined in Section 3.2 and recalled to be the fit below which new products are spawned and above which they are retained. Consider the case where a single innovation is devised in period $t$, by agent $a .^{22}$ The assumption of costless bargaining requires that $\omega_{t}^{*}$ be such that

$$
v_{t}^{\text {out }}+\frac{V_{t+1}^{a \in \mathcal{A}^{+}}+V_{t+1}^{\mathcal{A} \backslash\{a\}}}{1+\rho}=v_{t}^{\text {in }}\left(\omega_{t}^{*}\right)+\frac{V_{t+1}^{\mathcal{A}}}{1+\rho} .
$$

The second term on LHS recognizes that the date $t+1$ value of future innovations to the departing agent, $V_{t+1}^{a \in \mathcal{A}^{+}}$, will be determined by his being part of the set of agents $\mathcal{A}^{+}$of the new firm; the corresponding value to the remaining agents, $V_{t+1}^{\mathcal{A} \backslash\{a\}}$, likewise reflects agent $a$ 's departure. Note that neither the agent who would replace $a$ in $\mathcal{A}$ in case of spawning nor the agents who would join $a$ in $\mathcal{A}^{+}$in that same case are involved in the decision to spawn.

Using the homogeneity of agents and recalling from Equation 3.2 that $\left|\mathcal{A}^{+}\right|=|\mathcal{A}|=A$, we have $V_{t}^{\mathcal{A}}=V_{t}^{\mathcal{A}^{+}}, V_{t+1}^{a \in \mathcal{A}^{+}}=V_{t+1}^{\mathcal{A}^{+}} / A=V_{t+1}^{\mathcal{A}} / A$, and $V_{t+1}^{\mathcal{A} \backslash\{a\}}=\frac{A-1}{A} V_{t+1}^{\mathcal{A}}$. Combining, we have $V_{t+1}^{a \in \mathcal{A}^{+}}+V_{t+1}^{\mathcal{A} \backslash\{a\}}=V_{t+1}^{\mathcal{A}}$. Equation (11) can then be simplified to $v_{t}^{\text {out }}=v_{t}^{\text {in }}\left(\omega_{t}^{*}\right)$ : the threshold fit for a given innovation depends only on the value of that innovation; it does not depend on the values of future innovations. We have

\footnotetext{
${ }^{22}$ This assumption is without loss of generality: the decision to retain or to spawn is made independently for each innovation.
} 
Lemma 1 The threshold fit equals

$$
\omega_{t}^{*}=1-\frac{\rho \kappa_{t}}{\beta}
$$

A new product with organizational fit $\omega_{i}<1-\frac{\rho \kappa_{t}}{\beta}$ will be spawned to be introduced by a new firm; it will be introduced by the innovating firm otherwise. Figure 2 shows the value attributable to the introduction of a new product, as a function of the product's fit with the innovating firm's organizational form. The solid line represents the value if the new product should be introduced by the innovating firm, the dotted line if it should be spawned to be introduced by a new firm. The threshold fit naturally is that at which the two lines intersect: low-fit products are spawned, high-fit products are not.

The threshold fit, $\omega_{t}^{*}$, decreases in the discount rate, $\rho$, and in the set-up cost, $\kappa_{t}$; it increases in the value of organizational fit, $\beta$; it is unaffected by the value of skills. This is intuitive. Products with organizational fit below the threshold will be spawned, so the threshold determines the frequency of spawning. A higher discount rate and a higher set-up cost increase capitalized set-up costs, $\rho \kappa_{t}$; higher capitalized set-up costs decrease the attractiveness of spawning, for they are borne only in case of spawning. The frequency of spawning naturally increases if fit is more valuable, for only in case of spawning can there be perfect fit between firm organization and product. The value of skills does not affect the frequency of spawning, for skills have no differential impact on the value of the product spawned or retained.

Solving Equation (9) forward and using Equations (1), (8), (10), and (12) we obtain

$$
V_{t}^{\mathcal{A}}=\frac{1}{\xi} \sum_{\tau=1}^{\infty} \frac{x_{\tau}\left(v_{\tau}-\frac{x_{\tau}}{2}\right)}{(1+\rho)^{\tau}},
$$

where, using Equation (5), we have

$$
v_{t}=\frac{1}{\rho}\left[\alpha+\beta\left(\frac{1+\omega_{t}^{* 2}}{2}\right)\right] .
$$

We now add the value of those products that were successfully introduced by the firm prior to date $t$ to obtain the date $t$ value of the firm. It is

$$
\begin{aligned}
W_{t}^{\mathcal{A}} & =\sum_{i \in \mathcal{I}_{t}} \sum_{\tau=1}^{\infty} \frac{\alpha+\beta \omega_{i}}{(1+\rho)^{\tau}}+V_{t}^{\mathcal{A}} \\
& =I_{t} \frac{\alpha+\beta \bar{\omega}_{t}}{\rho}+V_{t}^{\mathcal{A}},
\end{aligned}
$$

where $I_{t}$ will be recalled to denote the number of products in firm $f$ 's portfolio at date $t$ and $\bar{\omega}_{t}$ represents the average fit between firm $f$ 's organizational form and the products in its portfolio, 
$\mathcal{I}_{t}$

$$
\bar{\omega}_{t} \equiv I_{t}^{-1} \sum_{i \in \mathcal{I}_{t}} \omega_{i}
$$

\section{$5 \quad$ Firm Characteristics}

In this section, we consider a number of firm characteristics such as the frequency of innovation, size, focus, and profitability. We then derive their comparative statics; these will be seen to revolve around the frequency of spawning, represented by the threshold fit, $\omega_{t}^{*}$.

- Frequency of Innovation. From Equations (10), (14), and (12), we have

$$
p_{t}=\frac{\gamma}{\xi \rho}\left[\alpha+\beta\left(\frac{1+\omega_{t}^{* 2}}{2}\right)\right] .
$$

We obtain

Proposition 1 The frequency of innovation increases in the values of skills ( $\alpha)$ and fit $(\beta)$ and in the bargaining power of innovators $(\gamma)$; it decreases in set-up costs $\left(\kappa_{t}\right)$.

The results of Proposition 1, as well as those of Propositions 2, 3, and 4 below, are summarized in Table 1, in which we have also reproduced the comparative statics of the frequency of spawning derived in Section 4. ${ }^{23}$ The frequency of innovation naturally increases in the values of skills $\left(d p_{t} / d \alpha>0\right)$ and fit $\left(d p_{t} / d \beta>0\right)$ : the more profitable are innovations, the more is invested in innovation, the larger is the frequency of innovation. In contrast, the frequency of innovation decreases in set-up costs $\left(d p_{t} / d \kappa_{t}<0\right)$ : higher set-up costs preclude the attainment of the greater fit made possible by spawning; they thereby decrease the profitability of, the investment in, and the frequency of innovation. Finally, the frequency of innovation increases in innovators' bargaining power $\left(d p_{t} / d \gamma>0\right)$ : higher bargaining power increases an innovator gain from innovation; it thereby increases the innovator's incentive to invest in innovation, in turn increasing the frequency of innovation.

- Firm Size. In our model, firm size at date $t$ is directly proportional to the number of product successfully introduced by the firm at that date, $I_{t}$. The expected size of firm $f$ at date $t$ equals

$$
\mathbb{E}\left[I_{t}\right]=1+\sum_{\tau=t_{f}+1}^{t-1} p_{\tau}\left(1-\omega_{\tau}^{*}\right) .
$$

\footnotetext{
${ }^{23}$ We establish but do not discuss the comparative statics with respect to the discount rate $(\rho)$ and the difficulty of innovation $(\xi)$; these present relatively little interest.
} 
The firm at date $t$ can be expected to have introduced new products and/or spawned new firms in periods $\tau, t_{f}<\tau<t$. Firm size starts at 1 , as the firm is born with a single product. We have

Proposition 2 Firm size increases in the value of skills ( $\alpha)$, set-up costs $\left(\kappa_{\tau}\right)$, and the bargaining power of innovators $(\gamma)$; it decreases in the value of fit $(\beta)$ where $\alpha>\beta / 4$.

The higher frequency of innovation due to more valuable skills $\left(d p_{t} / d \alpha>0\right)$ or higher bargaining power $\left(d p_{t} / d \gamma>0\right)$ increases firm size $\left(d \mathbb{E}\left[I_{t}\right] / d \alpha>0, d \mathbb{E}\left[I_{t}\right] / d \gamma>0\right)$ : more innovations devised means more innovations retained where spawning frequency remains unchanged $\left(d \omega_{t}^{*} / d \alpha=0\right)$; more innovations retained in turn means larger size. What is true for the value of skills is not necessarily true for that of fit: the increase in spawning frequency due to a greater value of fit $\left(d \omega_{t}^{*} / d \beta>0\right)$ may offset the increase in innovations following from that greater value $\left(d p_{t} / d \beta>0\right)$; the net effect is indeterminate. A sufficient condition for the former effect to dominate and for size to decrease in the value of fit $\left(d \mathbb{E}\left[I_{t}\right] / d \beta<0\right)$ is that the value of skills not be 'too small' relative to that of fit, $\alpha>\beta / 4$ : if $\alpha$ is not 'too small' and $p_{t}$ is not 'too small,' the infra-marginal effect of an increase in the value of fit $\left(-p_{t} d \omega_{t}^{*} / d \beta<0\right)$ dominates the marginal effect $\left(\left(1-\omega_{t}^{*}\right) d p_{t} / d \beta>0\right)$. We shall assume the condition holds in our discussion of the empirical evidence and the testable implications in Section 8. The opposing effects of decreased spawning frequency $\left(d \omega_{t}^{*} / d \kappa_{\tau}<0\right.$ for $\left.t_{f}<\tau<t\right)$ and decreased innovation frequency $\left(d p_{t} / d \kappa_{\tau}<0\right.$ for $\left.t_{f}<\tau<t\right)$ also apply in the case of increased set-up costs, but the former effect always dominates in such case: set-up costs have a much greater effect on spawning frequency than on the frequency of innovation in our model; size increases in set-up costs $\left(d \mathbb{E}\left[I_{t}\right] / d \kappa_{\tau}>0\right.$ for $\left.t_{f}<\tau<t\right)$.

- Firm Focus. We wish to measure firm f's focus, that is, the similarity or dissimilarity of the products in the firm's portfolio. Consider the average distance between the firm's original product, $\theta_{f}$, and all products subsequently introduced by the firm: the smaller is that distance, the more focused is the firm. Recalling that the firm's original product determines that firm's organizational form, $m_{f}=\theta_{f}$, that distance is also the average distance between the firm's organizational form and each of the firm's products. As organizational fit is the complement of the normalized distance between product and form (see Section 3.1), a natural measure of focus is then average organizational fit, $I_{t}^{-1} \sum_{i \in \mathcal{I}_{t}} \omega_{i}$, denoted $\bar{\omega}_{t}$ in Equation (16): the larger is average organizational fit, the more focused is the firm. We show that the expected focus of firm $f$ at a date $t$ equals

$$
\mathbb{E}\left[\bar{\omega}_{t}\right]=1-\frac{1}{2} \frac{\sum_{\tau=t_{f}+1}^{t-1} p_{\tau}\left(1-\omega_{\tau}^{*}\right)^{2}}{1+\sum_{\tau=t_{f}+1}^{t-1} p_{\tau}\left(1-\omega_{\tau}^{*}\right)} .
$$

Firm focus equals 1 at birth, as the single product with which the firm is born determines the firm's organizational form, $m_{f}=\theta_{f}$. We have 
Proposition 3 Firm focus increases in the value of fit ( $\beta)$; it decreases in the value of skills $(\alpha)$, set-up costs $\left(\kappa_{\tau}\right)$, and the bargaining power of innovators $(\gamma)$.

Focus decreases in the value of skills $\left(d \mathbb{E}\left[\bar{\omega}_{t}\right] / d \alpha<0\right)$ and in bargaining power $\left(d \mathbb{E}\left[\bar{\omega}_{t}\right] / d \gamma<0\right)$, a consequence of increased innovation frequency $\left(d p_{t} / d \alpha>0\right.$ and $\left.d p_{t} / d \gamma>0\right)$ : the innovations devised by a firm generically differ from that firm's organizational form; more innovation implies more difference, that is, less focus. This effect is offset by increased spawning frequency $\left(d \omega_{t}^{*} / d \beta>\right.$ $0)$ in the case of an increase in the value of fit: focus increases in the value of fit $\left(d \mathbb{E}\left[\bar{\omega}_{t}\right] / d \beta>0\right)$. The dominant effect of spawning frequency extends to the case of set-up costs: focus decreases in set-up costs $\left(d \mathbb{E}\left[\bar{\omega}_{t}\right] / d \kappa_{\tau}<0\right.$ for $\left.t_{f}<\tau<t\right)$, a consequence of decreased spawning frequency $\left(d \omega_{t}^{*} / d \kappa_{\tau}<0\right.$ for $\left.t_{f}<\tau<t\right)$.

- Profitability. We measure the profitability of firm $f$ at date $t$ as the total profit generated by all products in the firm's portfolio at that date, divided by the number such products. This measure recalls a firm's return on assets (ROA). The expected profitability of firm $f$ at date $t$ equals

$$
\mathbb{E}\left[R O A_{t}\right] \equiv \mathbb{E}\left[\sum_{i \in \mathcal{I}_{t}} \pi_{i} I_{t}^{-1}\right]=\alpha+\beta \mathbb{E}\left[\bar{\omega}_{t}\right] .
$$

Firm profitability equals $\alpha+\beta$ at birth, as focus then equals 1 . We have

Proposition 4 Profitability increases in the value of fit $(\beta)$; it decreases in set-up costs $\left(\kappa_{\tau}\right)$, and the bargaining power of innovators $(\gamma)$. Profitability may increase or decrease in the value of skills $(\alpha)$.

From $\mathbb{E}\left[R O A_{t}\right]=\alpha+\beta \mathbb{E}\left[\bar{\omega}_{t}\right]$ in Equation (20), changes in profitability due to changes in set-up costs and in bargaining power are entirely attributable to changes in focus. The indirect effect through focus of the value of fit on profitability $\left(\beta d \mathbb{E}\left[\bar{\omega}_{t}\right] / d \beta>0\right)$ is compounded by the direct effect of the value of fit on profitability $\left(\partial \mathbb{E}\left[R O A_{t}\right] / \partial \beta=\mathbb{E}\left[\bar{\omega}_{t}\right]>0\right)$; profitability increases in the value of fit $\left(d \mathbb{E}\left[R O A_{t}\right] / d \beta>0\right)$. There is countering rather than compounding for the value of skills: profitability may increase or decrease in the value of skills $\left(d \mathbb{E}\left[R O A_{t}\right] / d \alpha \gtrless 0\right)$; the indirect effect through focus $\left(\beta d \mathbb{E}\left[\bar{\omega}_{t}\right] / d \alpha<0\right)$ may or may not be offset by the direct effect $\left(\partial \mathbb{E}\left[R O A_{t}\right] / \partial \alpha=1>0\right)$.

\section{Spawning Dynamics and the Evolution of Firm Characteristics}

We now examine the evolution of firm characteristics over time. We first consider the case of constant set-up costs. Despite the constancy of set-up costs and other model parameters, firm size, 
focus, and profitability evolve over time, a consequence of the firm's growing portfolio of products. We then consider the case of increasing set-up costs. We derive the resulting spawning dynamics and examine their implications for the evolution of firm characteristics.

\subsection{Baseline Case: Constant Set-Up Cost}

We first consider the baseline case of constant set-up costs: $\kappa_{t}=\kappa$ for all $t$. The frequencies of spawning $\left(\omega_{t}^{*}\right)$ and of innovation $\left(p_{t}\right)$ clearly are constant over time in such case. Proposition 5 shows that even then, firm size $\left(\mathbb{E}\left[I_{t}\right]\right)$, focus $\left(\mathbb{E}\left[\bar{\omega}_{t}\right]\right)$, and profitability $\left(\mathbb{E}\left[R O A_{t}\right]\right)$ evolve over time.

Proposition 5 Where set-up costs are constant, firm size increases in age ( $t$ ) whereas firm focus and profitability decrease.

Size increases in age $\left(d \mathbb{E}\left[I_{t}\right] / d t>0\right)$ as the firm adds new products to the single product with which it was born; focus decreases $\left(d \mathbb{E}\left[\bar{\omega}_{t}\right] / d t<0\right)$ as innovations accumulate that are generically different from firm organizational form. ${ }^{24}$ The decrease of profitability in age $\left(d \mathbb{E}\left[R O A_{t}\right] / d t<0\right)$ is entirely attributable to the decrease of focus in age. ${ }^{25}$ In short, older firms' larger and more disparate product portfolios increase firm size and decrease firm focus and profitability.

\subsection{Increasing Set-Up Costs}

The assumption of constant set-up costs made in Section 6.1 implies that the frequency of spawning is constant over time. In order to avoid this counter-factual implication (Gompers, Lerner, and Scharfstein, 2005), we make in the present section the assumption that set-up costs increase over time:

Assumption $\mathbf{K}$ Set-up costs are increasing in time: $d \kappa_{t} / d t>0$.

We motivate Assumption $\mathrm{K}$ as follows: as a new industry develops and firms active in the industry acquire new knowledge through learning-by-doing for example, it becomes costlier for new firms seeking to enter the industry to acquire or replicate the body of knowledge necessary to operate successfully in the industry; set-up costs consequently increase over time. We have

Proposition 6 Assume $K$ holds. The frequencies of spawning and of innovation decrease in age (t), as do firm focus and profitability; firm size increases in age.

\footnotetext{
${ }^{24}$ Focus is maximal at birth; it tends to the long-run level $\lim _{t \rightarrow \infty} \mathbb{E}\left[\bar{\omega}_{t}\right]=1-\frac{\rho \kappa}{2 \beta}$.

${ }^{25}$ Profitability is maximal at birth; it tends to the long-run level $\lim _{t \rightarrow \infty} \mathbb{E}\left[R O A_{t}\right]=\alpha+\beta-\frac{\rho \kappa}{2}$.
} 
The threshold fit, $\omega_{t}^{*}$, varies over time because the set-up cost, $\kappa_{t}$, does; the former decreases over time as the latter increases. ${ }^{26}$ As the threshold fit determines the spawning frequency, the frequency of spawning decreases over time. The same holds true of the frequency of innovation, for the same reason as it does the threshold fit: as noted in the discussion that follows Proposition 1, higher set-up costs discourage innovation by precluding the attainment of the greater fit made possible by spawning.

Proposition 6 reproduces Gompers, Lerner, and Scharfstein's (2005) finding that spawning decreases in firm age: older firms tend to be active in older industries (Loderer, Neusser, and Waelchli, 2010), in which set-up costs are higher; these firms devise fewer innovations, of which a smaller fraction is spawned; the combined effect is to decrease spawning by older firms. Somewhat similarly to older firms' lower profitability, these firm's lesser spawning need not be associated with some form of decline; it is instead the reflection of the higher cost of setting up new firms in older industries, as represented by Assumption K.

The results for firm size, focus, and profitability are immediate from Proposition 5 combined with Propositions 2, 3, and 4, respectively: age's direct effect is compounded by its indirect effect through increased set-up costs.

\section{Entry}

In this section, we examine the extent of entry by spawning and compare the profitability of spawning entry with that of diversifying entry.

\subsection{Entry by Spawning}

We still assume that Assumption $\mathrm{K}$ holds. We recall that $F_{t}$ denotes the number of firms in existence at the beginning of period $t$. We denote by $N_{t}$ the number of firms spawned over the course of the preceding period, $t-1$; we denote by $s_{t-1} \equiv p_{t-1} \omega_{t-1}^{*}$ the expected, per-firm number of innovations devised and spawned over that period. We have $\mathbb{E}\left[F_{t}\right]=\left(1+s_{t-1}-\lambda\right) \mathbb{E}\left[F_{t-1}\right]$ and

$$
\mathbb{E}\left[N_{t}\right]=s_{t-1} \mathbb{E}\left[F_{t-1}\right]=s_{t-1} \prod_{\tau=1}^{\tau=t-2}\left(1+s_{\tau}-\lambda\right) .
$$

Our primary interest is in how entry due to spawning - represented by the number of spawned

\footnotetext{
${ }^{26}$ Formally, we have $\Delta \omega_{t}^{*} \equiv \omega_{t}^{*}-\omega_{t-1}^{*}=-\frac{\rho}{\beta} \Delta \kappa_{t}<0$, where the inequality is true by $\Delta \kappa_{t} \equiv \kappa_{t}-\kappa_{t-1}>0$.
} 
firms, $N_{t}$-varies over time. First-differencing expression (21) and rewriting, we obtain

$$
\Delta \mathbb{E}\left[N_{t}\right] \equiv \mathbb{E}\left[N_{t}\right]-\mathbb{E}\left[N_{t-1}\right] \gtrless 0 \Leftrightarrow s_{t-2}-\lambda-\frac{s_{t-2}}{s_{t-1}}+1 \gtrless 0 .
$$

Entry due to spawning increases over time where the rate of change in the number of existing firms dominates the rate of change in the number of innovations devised and spawned. It decreases

otherwise. The term $s_{t-2}-\lambda$ is the rate of change in the number of existing firms between $t-2$ to $t-1$. The term $s_{t-2} / s_{t-1}$ is the (inverse) rate of change in the number of innovations devised and spawned. Note that $s_{t}$ is decreasing in $t$, implying that $s_{t-2}-\lambda$ decreases in $t$ and that $s_{t-2} / s_{t-1}$ is larger than $1 .{ }^{27}$

We define $s_{\infty} \equiv \lim _{t \rightarrow \infty} s_{t}$ and assume that $s_{\infty}<\lambda$. As $s_{t}$ decreases in $t$, this assumption ensures that there exists some date $t^{\prime}$ such that $s_{\tau}<\lambda$ for all $\tau \geq t^{\prime}$. This in turn ensures that the number of existing firms declines for all $\tau \geq t^{\prime}$, because

$$
\mathbb{E}\left[\frac{F_{t+1}-F_{t}}{F_{t}}\right]=s_{t}-\lambda
$$

It is easy to show

Proposition 7 If Assumption $K$ holds and if $s_{\infty}<\lambda$, then entry by spawning eventually decreases over time. Entry by spawning initially increases if $s_{1}-\lambda>s_{1} / s_{2}-1$; it decreases monotonically over time if $s_{1}-\lambda<s_{1} / s_{2}-1$.

Proposition 7 can be interpreted as follows: the number of new firms entering the industry by spawning, $p_{t} \omega_{t}^{*} F_{t}$, depends on the frequency of innovation, the frequency of spawning, and the number of existing firms from which the new firms are spawned. As both the frequency of innovation and the frequency of spawning decrease over time, a decrease in the number of entrants necessarily occurs where there is a decrease in the number of existing firms. A sufficient condition for such decrease is that $s_{\infty}<\lambda$. We know from Condition (22) that there is nonetheless an initial increase in the number of entrants if $s_{1}-\lambda>s_{1} / s_{2}-1$, that is, if in the early stages of the industry the increase in the number of existing firms offsets the decrease in innovation and in spawning; there is no such initial increase otherwise.

\subsection{Diversifying Entry}

We compare the profitability of entry by spawning and diversifying entry. For that purpose, we distinguish between a firm spawned from a firm already active in the new industry and a firm active

\footnotetext{
${ }^{27}$ The result that $s_{t} \equiv p_{t} \omega_{t}^{*}$ is decreasing in $t$ is a direct consequence of the result that $p_{t}$ and $\omega_{t}^{*}$ are decreasing in $t$; this follows from Assumption $\mathrm{K}$.
} 
in another industry that decides to diversify into the new industry. We denote the spawned firm's values of skills and fit by $\alpha_{s}$ and $\beta_{s}$, respectively, and the diversifying firm's by $\alpha_{d}$ and $\beta_{d}$. We denote by $\omega_{i s}$ the fit that the spawning firm would have had, had it chosen to introduce the new product $\theta_{i}$ itself and by $\omega_{i d}$ the diversifying firm's fit. We interpret diversification from another industry to the new industry to imply $\omega_{i s}>\omega_{i d}$ : the organizational form of a firm already active in the new industry likely is more fitting the new product in that industry than the organizational form of a firm active in another industry. We no longer require Assumption K. We show

Proposition 8 Where diversifying entry occurs, diversifying firms have lower value of organizational fit than spawned firms, $\beta_{d}<\beta_{s}$. Spawning entry should therefore be more profitable than diversifying entry, unless offset by greater value of skills, $\alpha_{d}>\alpha_{s}+\beta_{s}-\beta_{d} \omega_{i d}>\alpha_{s}$.

A 'revealed-preference' type argument is used to conclude in the diversifying firm's lesser value of fit. Spawning achieves perfect organizational fit; a firm that eschews spawning even as it has lesser fit, $\omega_{i d}<\omega_{i s}<1$, reveals relatively little value for fit, $\beta_{d}<\beta_{s}$. The diversifying firm's lesser fit and lesser value of fit combine to imply that diversifying entry is less profitable than spawning entry, unless offset by the diversifying firm's greater value of skills, $\alpha_{d}>\alpha_{s}+\beta_{s}-\beta_{d} \omega_{i d}>\alpha_{s}$. Despite the lower profit attributable to fit $\left(\beta_{d} \omega_{i d}<\beta_{s}\right)$, the diversifying firm may nonetheless reap higher profit from introducing the new product if it should have greater value of skills: these do not depend on fit, and, therefore, are not hampered by the diversifying firm's lesser fit and value of fit.

\section{Empirical Evidence and Testable Implications}

We discuss some supporting empirical evidence and derive a number of testable implications. We first examine the relations between the endogenous variables that are spawning, focus, and profitability and the exogenous variables that are age, set-up costs, and the values of skills. We start with age $(t)$. Gompers, Lerner, and Scharfstein (2005) find that older firms spawn fewer new firms; Denis, Denis, and Sarin (1997) find that older firms are more diversified and Loderer and Waelchli (2009) find that they are less profitable. All three findings are consistent with the predictions of our model. The exact expression for the extent of spawning at date $t$ in our model is the product $s_{t} \equiv p_{t} \omega_{t}^{*}$ defined in Section 7 . We know $s_{t}$ to be decreasing in $t$, indirectly through $\kappa_{t}$; we also know focus, $\mathbb{E}\left[\bar{\omega}_{t}\right]$, and profitability, $\mathbb{E}\left[R O A_{t}\right]$, to be decreasing in $t$.

Gompers, Lerner, and Scharfstein (2005) find that firms that have higher patent quality spawn 
more; Franco and Filson (2006) find that firms that have higher knowhow spawn more. These two findings are consistent with the predictions of our model, regardless of whether patent quality and knowhow are viewed as being primarily in the nature of skills, $\alpha$, or in that of fit, $\beta: p_{t}, \omega_{t}^{*}$, and therefore $s_{t}$ are increasing in $\alpha$ and in $\beta .^{28}$

We now turn to examining the relations among the various endogenous variables that are spawning, focus, and profitability. The nature of such relations depends crucially on the specific exogenous variable driving the relations. Consider for example the relation between spawning and focus. From the results in Section 5 that spawning frequency $\left(\omega_{t}^{*}\right)$, the frequency of innovation $\left(p_{t}\right)$, and focus $\left(\mathbb{E}\left[\bar{\omega}_{t}\right]\right)$ increase in the value of fit $(\beta)$, we conclude that more focused firms spawn more when spawning is driven by the value of fit. Such is not the case where spawning is driven by the value of skills $(\alpha)$, for spawning increases whereas focus decreases in that value. ${ }^{29}$ Thus, empirical tests that examine the relation between spawning and focus may find contrasting results depending on whether the relation is driven primarily by the value of fit or that of skills.

Our model predicts the following. Where spawning is driven primarily by the value of fit, smaller, more innovative, and more focused firms spawn more and are more profitable. Where the driving force is the value of skills and profitability increases in that value, larger, more diversified firms innovate and spawn more and are more profitable. Where profitability decreases in the value of skills, larger, more diversified firms innovate and spawn more but are less profitable. These predictions may help reconcile otherwise contradictory empirical evidence.

Consider for example the relation between size and profitability or, more generally, value. ${ }^{30}$ Recent studies document a negative relation between these two endogenous variables. ${ }^{31}$ Yet, this has not always been so: Hall and Weiss (1967) document a positive such relation for the time period 1956-1962. The distinction between the value of skills and that of fit may help reconcile these contrasting results, if profitability should be increasing in the value of skills $\left(d \mathbb{E}\left[R O A_{t}\right] / d \alpha>0\right)$ : it

\footnotetext{
${ }^{28}$ An obvious question is how to empirically measure the values of skills and fit. An example for a proxy for skills is Gompers, Lerner, and Scharfstein's (2005) citation-based value of patents; fit on the other hand could e.g. be proxied by Brynjolfsson, Hitt, and Yang's (2002) measure of organizational capital.

${ }^{29}$ Although spawning frequency is unaffected by the value of skills, spawning increases in that value because of increased innovativeness.

${ }^{30}$ Note that the comparative statics of profitability, $\mathbb{E}\left[R O A_{t}\right]$, are the same as those of value, $W_{t}^{\mathcal{A}}$, where profitability increases in the value of fit $\left(d \mathbb{E}\left[R O A_{t}\right] / d \alpha>0\right)$. As seen in Equation (15), $W_{t}^{\mathcal{A}}$ is the sum of the value of assets in place and that of growth opportunities, $V_{t}^{\mathcal{A}}$. That the former has the same comparative statics in expectation as $\mathbb{E}\left[R O A_{t}\right]$ is immediate from the definition of $\mathbb{E}\left[R O A_{t}\right]$; that the latter has the same comparative statics follows from the dependence of $V_{t}^{\mathcal{A}}$ on $x_{t}$ (see Equation (13)), which can easily be seen from $x_{t}$ 's determination of $p_{t}$ (see Equation (8)) to have the same comparative statics as $\mathbb{E}\left[R O A_{t}\right]$ where $d \mathbb{E}\left[R O A_{t}\right] / d \alpha>0$.

${ }^{31}$ See most recently Loderer and Waelchli (2009).
} 
is conceivable that the relation between size and profitability was driven in earlier periods primarily by the value of skills; the value of fit only later may have become of primary importance, accounting for the reversal of the relation.

The same distinction may help account for the contrasting evidence regarding the relation between focus and profitability or value. Most studies have documented a positive relation, but a few a have documented a negative relation. In particular, an argument has been made that related diversification creates value. ${ }^{32}$ Suppose that the decision to remain focused is driven primarily by a large value of fit, that to diversify by a large value of skills. Both values increase profitability where profitability increases in the value of skills $\left(d \mathbb{E}\left[R O A_{t}\right] / d \alpha>0\right)$, but the former keeps focus high whereas the latter decreases it. The relation between focus and profitability is therefore positive when driven by the value of fit, negative when driven by that of skills. To the extent that there are few truly general skills, and that a diversifying firm's skills may be more directly applicable to related than to unrelated industries, the value of skills may account for the positive relation between related diversification and profitability/value.

We now turn to entry. Proposition 7 establishes that entry by spawning passes the near-litmus tests of first increasing and then decreasing over time (Agarwal and Gort, 1996; Klepper, 1996) or decreasing throughout (Klepper). Returning to the interpretation of $\alpha$ and $\beta$ as the values of general and specific resources, respectively, Proposition 8 shows that it is firms with fewer specific (lower $\beta$ ) and more general resources (higher $\alpha$ ) that are generally the ones that diversify. ${ }^{33}$ It also shows that, unless a diversifying entrant has markedly higher skills than a competing spawned entrant, entry should generally be more profitable to the latter. ${ }^{34}$

Interestingly, support for Proposition 8 is provided by one instance of a new industry that did not grow by spawning, consumer electronics in Tokyo. Tokyo's factories "pour a disproportionate part of the world's output of television sets, VCRs, camcorders, smart cameras, laptop computers, feature telephones, fax machines, CD players, hi-fi amplifiers, music synthesizers, and all the rest of the electronic cornucopia that [...] seems to flood the entire world" (Hall, 1998, p. 455). Much of these are produced by long-established firms such as Toshiba, NEC, and Fujitsu, makers of electrical goods and telephone and telegraph equipment well before the invention of the transistor. The contrast with the US is striking: where the new electronics industry brought forth a new set of firms in the US, the industry to a large extent grew within existing firms in Japan. ${ }^{35}$ The obvious

\footnotetext{
${ }^{32}$ See Montgomery (1994) and Villalonga (2004).

${ }^{33}$ See for example Chatterjee and Wernerfelt (1991).

${ }^{34}$ Klepper and Thompson (2009) show that spawned firms have higher survival probability.

${ }^{35}$ There were of course some new firms in Japan too, e.g., Sony.
} 
question is why.

Proposition 8 suggests one possible answer: diversifying entry dominates where diversifying firms' skills - their general resources - are more valuable. Are Japanese firms' skills more valuable, then, or were they at least so in the years that saw the industry grow and prosper? There is some evidence to that effect: there is the view that large Japanese firms' practice of transferring researchers and engineers between their research and manufacturing divisions increased horizontal communication to such an extent as to confer upon large Japanese firms "an extraordinary ability - long common in small innovative firms, but unusual in large highly structured ones - to combine different kinds of thinking in the development of new products and new processes ... [ that made possible] "a process of organizational learning which allows large corporations to enter new technological fields in an 'amoeba-like' way" (Hall, 1998, p. 477). The quote makes clear both the value and the versatility of Japanese firms' resources; large, diversified Japanese firms have - or perhaps had-high $\alpha_{d}$.

\section{Conclusion}

Entrepreneurial spawning is the process whereby an existing firm gives birth to a new firm set up by one or more employees departed from the existing firm. Although the phenomenon of spawning itself has been quite extensively studied, its implications for firm characteristics such as size, focus, profitability, and innovativeness have received little attention. Our paper aims at filling this gap.

We motivate spawning by the desire to achieve organizational fit, that is, the degree to which a firm's organization is adapted to the needs of its product portfolio. Spawning occurs where an employee who develops a new product finds it beneficial to start a new firm to commercialize that product, because the product presents little fit with the organizational form of the firm at which the employee originally is employed. There is a trade-off between organizational fit and the cost to setting up a new firm.

From this basic trade-off, we derive the implications of spawning for firm size, profitability, focus, and innovativeness. We analyze how the values of firm skills and organizational fit, the cost of setting up a new firm, firm age, and the bargaining power of innovating employees affect the aforementioned firm characteristics. Firms that have higher value of skills spawn more, as do firms that have higher value of organizational fit. As firms mature, they spawn less and devise fewer innovations, they are less profitable and more diversified. Focus and profitability are positively related where spawning is driven by the value of organizational fit; they may be negatively related 
where spawning is driven by the value of firm skills.

We examine the extent and the profitability of entry by spawning into a new industry. In line with extant empirical findings, we show that entry by spawning is more profitable than diversifying entry. Our model accounts for much of the empirical evidence on the relation between spawning and firm characteristics; it suggests new empirical tests based upon the distinction between the value of skills and that of fit. 


\section{Appendix}

Proof of (8): Differentiating (7) with respect to $q_{t}$, using (1), and recalling that $V_{t+1}^{a}$ does not depend on $q_{t}$, we have $\frac{\partial V_{t}^{a}}{\partial q_{t}}=x_{t}-p_{t} \xi$; equating to 0 we obtain $q_{t}=x_{t} / \zeta$.

Proof of (14): Evaluating $v_{t}$ in Equation (5), we obtain

$$
v_{t}=\frac{\alpha+\beta}{\rho}-\kappa_{t}-\left(1-\omega_{t}^{*}\right)\left[\frac{\beta}{\rho}\left(\frac{1-\omega_{t}^{*}}{2}\right)-\kappa_{t}\right] .
$$

From (12), we have $\kappa_{t}=\frac{\beta}{\rho}\left(1-\omega_{t}^{*}\right)$. Substituting $\kappa_{t}$ into (24), yields (14).

Proof of (18): A new product is introduced at date $\tau+\epsilon$ with probability $p_{\tau}\left(1-\omega_{\tau}^{*}\right)$ by the innovating firm. Aggregating products introduced over time yields $\mathbb{E}\left[I_{t}\right]=1+\sum_{\tau=t_{f}+1}^{t-1} p_{\tau}\left(1-\omega_{\tau}^{*}\right)$.

Proof of (19): Calculate $\mathbb{E}\left[\bar{\omega}_{t}\right]$ as the weighted average of every period's expected product fit

$$
\mathbb{E}\left[\bar{\omega}_{t}\right]=\frac{1+\sum_{\tau=t_{f}+1}^{t-1} p_{\tau} \int_{\omega_{\tau}^{*}}^{1} \omega_{i} d \omega_{i}}{1+\sum_{\tau=t_{f}+1}^{t-1} p_{\tau} \int_{\omega_{\tau}^{*}}^{1} d \omega_{i}}=\frac{1+\sum_{\tau=t_{f}+1}^{t-1} p_{\tau}\left(1-\omega_{\tau}^{*}\right)\left(1-\frac{1-\omega_{\tau}^{*}}{2}\right)}{1+\sum_{\tau=t_{f}+1}^{t-1} p_{\tau}\left(1-\omega_{\tau}^{*}\right)},
$$

which yields (19).

Proof of Propositions 1 to 4: Using $p_{t}$ in (10), $v_{t}$ in (14) and $\omega_{\tau}^{*}$ in (12), we have

$$
p_{t}=\frac{\gamma}{\xi \rho}\left[\alpha+\frac{\beta}{2}\left(1+\left[1-\frac{\rho \kappa_{t}}{\beta}\right]^{2}\right)\right] \text {. }
$$

It is immediate that $\frac{d p_{t}}{d \alpha}>0, \frac{d p_{t}}{d \beta}>0, \frac{d p_{t}}{d \kappa_{t}}<0, \frac{d p_{t}}{d \rho}<0, \frac{d p_{t}}{d \gamma}>0$, and $\frac{d p_{t}}{d \xi}<0$. Substitute $\omega_{\tau}^{*}$ in (12) into $p_{\tau}\left(1-\omega_{\tau}^{*}\right)$ to obtain

$$
p_{\tau}\left(1-\omega_{\tau}^{*}\right)=\frac{\gamma \kappa_{\tau}}{2 \xi}\left[\frac{2 \alpha}{\beta}+\left(1+\left[1-\frac{\rho \kappa_{\tau}}{\beta}\right]^{2}\right)\right] .
$$

Substitute $p_{\tau}\left(1-\omega_{\tau}^{*}\right)$ in (27) into (25) to obtain

$$
\mathbb{E}\left[\bar{\omega}_{t}\right]=1-\frac{1}{2} \frac{\sum_{\tau=t_{f}+1}^{t-1} \frac{\gamma \kappa_{\tau}}{2 \xi}\left[\frac{2 \alpha}{\beta}+\left(1+\omega_{\tau}^{* 2}\right)\right]\left(1-\omega_{\tau}^{*}\right)}{1+\sum_{\tau=t_{f}+1}^{t-1} \frac{\gamma \kappa_{\tau}}{2 \xi}\left[\frac{2 \alpha}{\beta}+\left(1+\omega_{\tau}^{* 2}\right)\right]} .
$$

Denote $L \equiv \frac{\gamma}{2 \xi}, M_{t} \equiv \sum_{\tau=t_{f}+1}^{t-1} \kappa_{\tau}\left(1+\omega_{\tau}^{* 2}\right)\left(1-\omega_{\tau}^{*}\right), N_{t} \equiv \sum_{\tau=t_{f}+1}^{t-1} \kappa_{\tau}\left(1+\omega_{\tau}^{* 2}\right)$ and $Q_{t} \equiv \sum_{\tau=t_{f}+1}^{t-1} \kappa_{\tau} \frac{2 \alpha}{\beta}$. Then $\mathbb{E}\left[\bar{\omega}_{t}\right]=1-\frac{1}{2} \frac{L\left(M_{t}+Q_{t}\right)}{1+L\left(N_{t}+Q_{t}\right)}$.

Substitute $p_{\tau}\left(1-\omega_{\tau}^{*}\right)$ in (27) into $\mathbb{E}\left[I_{t}\right]=1+\sum_{\tau=t_{f}+1}^{t-1} p_{\tau}\left(1-\omega_{\tau}^{*}\right)$ to obtain

$$
\mathbb{E}\left[I_{t}\right]=1+\sum_{\tau=t_{f}+1}^{t-1} \frac{\gamma \kappa_{\tau}}{2 \xi}\left[\frac{2 \alpha}{\beta}+\left(1+\omega_{\tau}^{* 2}\right)\right] .
$$

Then $\mathbb{E}\left[I_{t}\right]=1+L\left(N_{t}+Q_{t}\right)$.

- For $\Xi \in\{\alpha, \beta, \rho\}$, we have $\frac{d \mathbb{E}\left[\bar{\omega}_{t}\right]}{d \Xi}=E(\Xi)$, where

$$
\begin{aligned}
E(\Xi) & \equiv \frac{-L A_{t}(\Xi)}{2\left(1+L\left(N_{t}+Q_{t}\right)\right)^{2}}, \\
A_{t}(\Xi) & \equiv\left(1+L\left(N_{t}+Q_{t}\right)\right) \frac{d M_{t}}{d \Xi}-L\left(M_{t}+Q_{t}\right) \frac{d N_{t}}{d \Xi}+\left(1+L\left(N_{t}-M_{t}\right)\right) \frac{d Q_{t}}{d \Xi} .
\end{aligned}
$$


Now, $1+L\left(N_{t}+Q_{t}\right)>0, L\left(M_{t}+Q_{t}\right)>0$ and $1+L\left(N_{t}-M_{t}\right)>0\left(\right.$ given that $N_{t}-M_{t}=\sum_{\tau=t_{f}+1}^{t-1} \kappa_{\tau}\left(1+\omega_{\tau}^{* 2}\right) \omega_{\tau}^{*}>$ $0)$. Also, $\frac{d M_{t}}{d \Xi}=-\sum_{\tau=t_{f}+1}^{t-1} \kappa_{\tau}\left(2 \omega_{\tau}^{* 2}+\left(1-\omega_{\tau}^{*}\right)^{2}\right) \frac{d \omega_{\tau}^{*}}{d \Xi}, \frac{d N_{t}}{d \Xi}=2 \sum_{\tau=t_{f}+1}^{t-1} \kappa_{\tau} \omega_{\tau} \frac{d \omega_{\tau}^{*}}{d \Xi}$ and $\frac{d Q_{t}}{d \Xi}=2 \sum_{\tau=t_{f}+1}^{t-1} \kappa_{\tau} \frac{d(\alpha / \beta)}{d \Xi}$. - For $\Xi=\alpha$ : We have $\frac{d \omega_{\tau}^{*}}{d \alpha}=0$ and $\frac{d(\alpha / \beta)}{d \alpha}=\frac{1}{\beta}$. So, $\frac{d M_{t}}{d \alpha}=\frac{d N_{t}}{d \alpha}=0$ and $\frac{d Q_{t}}{d \alpha}=\frac{2}{\beta} \sum_{\tau=t_{f}+1}^{t-1} \kappa_{\tau}>0$. Therefore, $A_{t}(\alpha)>0$. Consequently, $\frac{d \mathbb{E}\left[\bar{\omega}_{t}\right]}{d \alpha}<0$.

Furthermore, $\frac{d \mathbb{E}\left[R O A_{t}\right]}{d \alpha}=1+\beta \frac{d \mathbb{E}\left[\bar{\omega}_{t}\right]}{d \alpha}=1-\frac{L\left(1+L\left(N_{t}-M_{t}\right)\right)}{\left(1+L\left(N_{t}+Q_{t}\right)\right)^{2}} \sum_{\tau=t_{f}+1}^{t-1} \kappa_{\tau}$, where only $Q_{t}$ is increasing in $\alpha$. So, there exists an $\alpha^{*}$ such that $\frac{d \mathbb{E}\left[R O A_{t}\right]}{d \alpha}<0$ for all $\alpha<\alpha^{*}$, and $\frac{d \mathbb{E}\left[R O A_{t}\right]}{d \alpha} \geq 0$ for all $\alpha \geq \alpha^{*}$.

Finally, $\frac{d \mathbb{E}\left[I_{t}\right]}{d \alpha}=L\left(\frac{d N_{t}}{d \alpha}+\frac{d Q_{t}}{d \alpha}\right)>0$.

- For $\Xi=\beta$ : We have $\frac{d \omega_{\tau}^{*}}{d \beta}=\frac{\rho \kappa_{t}}{\beta^{2}}>0$ and $\frac{d(\alpha / \beta)}{d \beta}=\frac{-\alpha}{\beta^{2}}<0$. So, $\frac{d M_{t}}{d \beta}<0, \frac{d N_{t}}{d \beta}>0$ and $\frac{d Q_{t}}{d \beta}<0$. Therefore, $A_{t}(\beta)<0$. Consequently, $\frac{d \mathbb{E}\left[\bar{\omega}_{t}\right]}{d \beta}>0$. Furthermore, $\frac{d \mathbb{E}\left[R O A_{t}\right]}{d \beta}=\beta \frac{d \mathbb{E}\left[\bar{\omega}_{t}\right]}{d \beta}+\mathbb{E}\left[\bar{\omega}_{t}\right]>0$.

$$
\frac{d \mathbb{E}\left[I_{t}\right]}{d \beta}=\sum_{\tau=t_{f}+1}^{t-1} \frac{\gamma \kappa_{\tau}}{\xi}\left[-\frac{\alpha}{\beta^{2}}+\left[1-\frac{\rho \kappa_{\tau}}{\beta}\right] \frac{\rho \kappa_{t}}{\beta^{2}}\right]=\sum_{\tau=t_{f}+1}^{t-1} \frac{\gamma \kappa_{\tau}}{\beta \xi}\left[-\frac{\alpha}{\beta}+\left(1-\omega_{\tau}^{*}\right) \omega_{\tau}^{*}\right] .
$$

Therefore, $\frac{d \mathbb{E}\left[I_{t}\right]}{d \beta}<0$ iff $-\alpha / \beta+\left[1-\omega_{\tau}^{*}\right] \omega_{\tau}^{*}<0$ for all $\tau$. The sufficient condition $\alpha / \beta>1 / 4$ is obtained by noting that $\left[1-\omega_{\tau}^{*}\right] \omega_{\tau}^{*}$ is maximized at $\omega_{\tau}^{*}=1 / 2$.

- For $\Xi=\rho$ : We have $\frac{d \omega_{\tau}^{*}}{d \rho}=\frac{-\kappa_{t}}{\beta}<0$ and $\frac{d(\alpha / \beta)}{d \rho}=0$. So, $\frac{d M_{t}}{d \rho}>0, \frac{d N_{t}}{d \rho}<0$ and $\frac{d Q_{t}}{d \rho}=0$. Therefore, $A_{t}(\rho)>0$. Consequently, $\frac{d \mathbb{E}\left[\bar{\omega}_{t}\right]}{d \rho}<0$. Furthermore, $\frac{d \mathbb{E}\left[R O A_{t}\right]}{d \rho}=\beta \frac{d \mathbb{E}\left[\bar{\omega}_{t}\right]}{d \rho}<0$. Finally, $\frac{d \mathbb{E}\left[I_{t}\right]}{d \rho}=L\left(\frac{d N_{t}}{d \rho}+\frac{d Q_{t}}{d \rho}\right)<0$.

- For $\kappa_{\tau}$, where $\tau \in\left(t_{f}, t\right)$, we have $\frac{d \mathbb{E}\left[\bar{\omega}_{t}\right]}{d \kappa_{\tau}}=E\left(\kappa_{\tau}\right)$. Here, $\frac{d M_{t}}{d \kappa_{\tau}}=\left(1+\omega_{\tau}^{* 2}\right)\left(1-\omega_{\tau}^{*}\right)-\kappa_{\tau}\left(2 \omega_{\tau}^{* 2}+\left(1-\omega_{\tau}^{*}\right)^{2}\right) \frac{d \omega_{\tau}^{*}}{d \kappa_{\tau}}$, $\frac{d N_{t}}{d \kappa_{\tau}}=\left(1+\omega_{\tau}^{* 2}\right)+2 \kappa_{\tau} \omega_{\tau} \frac{d \omega_{\tau}^{*}}{d \kappa_{\tau}}$ and $\frac{d Q_{t}}{d \kappa_{\tau}}=2 \frac{\alpha}{\beta}>0$. As $\frac{d \omega_{\tau}^{*}}{d \kappa_{\tau}}=\frac{-\rho}{\beta}=\frac{-\left(1-\omega_{\tau}^{*}\right)}{\kappa_{\tau}}$, we have, $\frac{d M_{t}}{d \kappa_{\tau}}=2\left(1+\omega_{\tau}^{* 2}\right)(1-$ $\left.\omega_{\tau}^{*}\right)>0, \frac{d N_{t}}{d \kappa_{\tau}}=\omega_{\tau}^{* 2}+\left(1-\omega_{\tau}^{*}\right)^{2}>0$. Then,

$$
\begin{aligned}
A_{t}\left(\kappa_{\tau}\right) & =2\left(1+\omega_{\tau}^{* 2}\right)\left(1-\omega_{\tau}^{*}\right)+\left(1+L\left(N_{t}-M_{t}\right)\right) 2 \frac{\alpha}{\beta} \\
& \left.+L\left(N_{t}+Q_{t}\right)\right)\left[2\left(1+\omega_{\tau}^{* 2}\right)\left(1-\omega_{\tau}^{*}\right)\right]-L\left(M_{t}+Q_{t}\right)\left[\omega_{\tau}^{* 2}+\left(1-\omega_{\tau}^{*}\right)^{2}\right] .
\end{aligned}
$$

The first two terms on the RHS of (33) are positive. Now, $N_{t} \geq M_{t}$ and $2\left(1+\omega_{\tau}^{* 2}\right)\left(1-\omega_{\tau}^{*}\right) \geq 2-2 \omega_{\tau}+$ $2 \omega_{\tau}^{* 2} \geq \omega_{\tau}^{* 2}+\left(1-\omega_{\tau}^{*}\right)^{2}$. So, the sum of the last two terms on the RHS of $(33)$ is positive. Therefore, $A_{t}\left(\kappa_{\tau}\right)>$ 0 . Consequently, $\frac{d \mathbb{E}\left[\bar{\omega}_{t}\right]}{d \kappa_{\tau}}<0$. Furthermore, $\frac{d \mathbb{E}\left[R O A_{t}\right]}{d \kappa_{\tau}}=\beta \frac{d \mathbb{E}\left[\bar{\omega}_{t}\right]}{d \kappa_{\tau}}<0$. Finally, $\frac{d \mathbb{E}\left[I_{t}\right]}{d \kappa_{\tau}}=L\left(\frac{d N_{t}}{d \kappa_{\tau}}+\frac{d Q_{t}}{d \kappa_{\tau}}\right)>0$.

- For $\Xi \in\{\gamma, \xi\}$, We have $\frac{d \omega_{\tau}^{*}}{d \Xi}=0$, so $\frac{d M_{t}}{d \Xi}=\frac{d N_{t}}{d \Xi}=0$, and $\frac{d Q_{t}}{d \Xi}=0$. Then $\frac{d L}{d \gamma}=\frac{1}{2 \xi}$ and $\frac{d L}{d \xi}=\frac{-\gamma}{2 \xi^{2}}$. Now, $\mathbb{E}\left[\bar{\omega}_{t}\right]=1-\frac{1}{2} \frac{M_{t}+Q_{t}}{L^{-1}+N_{t}+Q_{t}}, \mathbb{E}\left[I_{t}\right]=1+L\left(N_{t}+Q_{t}\right)$ and $\mathbb{E}\left[R O A_{t}\right]=\alpha+\beta\left(1-\frac{1}{2} \frac{M_{t}+Q_{t}}{L^{-1}+N_{t}+Q_{t}}\right)$. Therefore, $\frac{d \mathbb{E}\left[\bar{\omega}_{t}\right]}{d \gamma}<0, \frac{d \mathbb{E}\left[I_{t}\right]}{d \gamma}>0$, and $\frac{d \mathbb{E}\left[R O A_{t}\right]}{d \gamma}<0$. Also, $\frac{d \mathbb{E}\left[\bar{\omega}_{t}\right]}{d \xi}>0, \frac{d \mathbb{E}\left[I_{t}\right]}{d \xi}<0$, and $\frac{d \mathbb{E}\left[R O A_{t}\right]}{d \xi}>0$.

Proof of Propositions 5 and 6: Building on the proof of Propositions 1 to 4 , denote $\Delta \mathbb{E}\left[\bar{\omega}_{t}\right] \equiv$ $\mathbb{E}\left[\bar{\omega}_{t}\right]-\mathbb{E}\left[\bar{\omega}_{t-1}\right]$ and $K_{t} \equiv N_{t}-M_{t}$. Given that $\Delta M_{t} \equiv M_{t}-M_{t-1}=\kappa_{t-1}\left(1+\omega_{t-1}^{* 2}\right)\left(1-\omega_{t-1}^{*}\right), \Delta N_{t} \equiv$ $N_{t}-N_{t-1}=\kappa_{t-1}\left(1+\omega_{t-1}^{* 2}\right), \Delta Q_{t} \equiv Q_{t}-Q_{t-1}=\kappa_{t-1} \frac{2 \alpha}{\beta}$, and $\Delta K_{t} \equiv K_{t}-K_{t-1}=\kappa_{t-1}\left(1+\omega_{t-1}^{* 2}\right) \omega_{t-1}^{*}$, we obtain

$$
\Delta \mathbb{E}\left[\bar{\omega}_{t}\right]=\frac{L\left(L \Delta N_{t}\left[M_{t-1}-\frac{\Delta M_{t}}{\Delta N_{t}} N_{t-1}\right]+L \Delta Q_{t}\left[\frac{\Delta K_{t}}{\Delta Q_{t}} Q_{t-1}-K_{t-1}\right]-\Delta M_{t}-\Delta Q_{t}\right)}{2\left[1+L\left(N_{t}+Q_{t}\right)\right]\left[1+L\left(N_{t-1}+Q_{t-1}\right)\right]} .
$$

In the case $\kappa_{\tau}=\kappa$ for all $\tau, K_{t-1}=\frac{\Delta K_{t}}{\Delta Q_{t}} Q_{t-1}$ and $M_{t-1}=\frac{\Delta M_{t}}{\Delta N_{t}} N_{t-1}$. In the Case $\kappa_{\tau}>\kappa_{\tau-1}$ for all $\tau, K_{t-1}=\sum_{\tau=t_{f}+1}^{t-2} \kappa_{\tau}\left(1+\omega_{\tau}^{* 2}\right) \omega_{\tau}^{*}>\sum_{\tau=t_{f}+1}^{t-2} \kappa_{\tau}\left(1+\omega_{t-1}^{* 2}\right) \omega_{t-1}^{*}=\frac{\Delta K_{t}}{\Delta Q_{t}} Q_{t-1}$ and $M_{t-1}=$ 
$\sum_{\tau=t_{f}+1}^{t-2} \kappa_{\tau}\left(1+\omega_{\tau}^{* 2}\right)\left(1-\omega_{\tau}^{*}\right)<\sum_{\tau=t_{f}+1}^{t-2} \kappa_{\tau}\left(1+\omega_{\tau}^{* 2}\right)\left(1-\omega_{t-1}^{*}\right)=\frac{\Delta M_{t}}{\Delta N_{t}} N_{t-1}$. So in both cases, $\Delta \mathbb{E}\left[\bar{\omega}_{t}\right]<$ 0 . Denoting $\Delta \mathbb{E}\left[R O A_{t}\right] \equiv \mathbb{E}\left[R O A_{t}\right]-\mathbb{E}\left[R O A_{t-1}\right]=\beta \Delta \mathbb{E}\left[\bar{\omega}_{t}\right]$, we have $\Delta \mathbb{E}\left[R O A_{t}\right]<0$. Finally, denoting $\Delta \mathbb{E}\left[I_{t}\right] \equiv \mathbb{E}\left[I_{t}\right]-\mathbb{E}\left[I_{t-1}\right]$, we have $\Delta \mathbb{E}\left[I_{t}\right]=L\left(\Delta N_{t}+\Delta Q_{t}\right)>0$.

Proof of (22): From (21), we have

$$
\Delta \mathbb{E}\left[N_{t}\right] \equiv \mathbb{E}\left[N_{t}\right]-\mathbb{E}\left[N_{t-1}\right]=\left[s_{t-1}\left(1+s_{t-2}-\lambda\right)-s_{t-2}\right] \prod_{\tau=1}^{\tau=t-3}\left(1+s_{\tau}-\lambda\right),
$$

from which (22) is immediate.

Proof of Proposition 8: That the firm already active in the new industry chooses to spawn implies $\omega_{i s}<1-\frac{\rho \kappa_{t}}{\beta_{s}}$. That the diversifying firm chooses not to spawn implies $\omega_{i d}>1-\frac{\rho \kappa_{t}}{\beta_{d}}$.

Together with the inequality $\omega_{i s}>\omega_{i d}$, the two preceding inequalities imply $\beta_{s}>\beta_{d}$. The per period profit to the spawned firm from introducing product $\theta_{i}$ is $\alpha_{s}+\beta_{s}$; that to the diversifying firm is $\alpha_{d}+\beta_{d} \omega_{i d}$. As $\omega_{i d}<1$ and $\beta_{d}<\beta_{s}$, it is clear that $\alpha_{d}+\beta_{d} \omega_{i d}<\alpha_{s}+\beta_{s}$, unless $\alpha_{d}>\alpha_{s}+\beta_{s}-\beta_{d} \omega_{i d}>\alpha_{s}$. 


\section{References}

Agarwal, R., R. Echambadi, A.M. Franco, and M.B. Sarkar, 2004, Knowledge Transfer Through Inheritance: Spin-Out Generation, Growth, and Survival, Academy of Management Journal 47, 501-522.

Agarwal, R. and M. Gort, 1996, The Evolution of Markets and Entry, Exit and Survival of Firms, Review of Economics and Statistics 78, 489-498.

Amador, M. and A. Landier, 2003, Entrepreneurial Pressure and Innovation, Mimeo, Graduate School of Business, Stanford University.

Anton, J. J. and D. A. Yao, 1995, Start-Ups, Spin-Offs, and Internal Projects, Journal of Law, Economics, and Organization 11, 362-378.

Berger, P. G. and E. Ofek, 1995, Diversification's Effect on Firm Value, Journal of Financial Economics $37,39-65$.

Bernardo, A.E. and B. Chowdhry, 2002, Resources, Real Options, and Corporate Strategy, Journal of Financial Economics 63, 211-234.

De Bettignies, J. and G. Chemla, 2008, Corporate Venture Capital: The Upside of Failure and Competition for Talent, Management Science, 54, 505-21.

Brynjolfsson, E., L.M. Hitt, S. Yang, 2002, Intangible Assets: Computers and Organizational Capital, Brookings Papers on Economic Activity, 137-181.

Buenstorf, G. and S. Klepper, 2009, Heritage and Agglomeration: The Akron Tyre Cluster Revisited, Economic Journal 119, 705-733.

Campa, J.M. and S. Kedia, 2002, Explaining the Diversification Discount, Journal of Finance 57, 17311762 .

Carroll, G.R. and M.T. Hannan, 2000, The Demography of Corporations and Industries, Princeton University Press, Princeton.

Cassiman, B. and M. Ueda, 2006, Optimal Project Rejection and New Firm Start-Ups, Management Science 52, 262-275.

Chatterjee, S. and B. Wernerfelt, 1991, The Link Between Resources and Type of Diversification: Theory and Evidence, Strategic Management Journal 12, 33-48.

Christensen, C.M., 1993, The Rigid Disk Drive Industry: A History of Commercial and Technological Turbulence, Business History Review 67, 531-588.

Christensen, C., 1997, The Innovator's Dilemma: When New Technologies Cause Great Firms to Fail, Harvard Business School Press, Boston.

Coad, A., 2009, The Growth of Firms: A Survey of Theories and Empirical Evidence, New Perspectives on the Modern Corporation, Elgar, Cheltenham.

Denis, D.J., D.K. Denis, and A. Sarin, 1997, Agency Problems, Equity Ownership, and Corporate Diversification, Journal of Finance 52, 135-160. 
Fluck, Z. and A.W. Lynch, 1999, Why Do Firms Merge and Then Divest? A Theory of Financial Synergy, Journal of Business 72, 319-346.

Franco, A. and D. Filson, 2006, Spin-Outs: Knowledge Diffusion Through Employee Mobility, Rand Journal of Economics 37, 841-860.

Gertner, R.H., Scharfstein, D.S., and J.C. Stein, 1994, Internal versus External Capital Markets, Quarterly Journal of Economics 109, 1211-1230.

Gomes, J. and D. Livdan, 2004, Optimal Diversification: Reconciling Theory and Evidence, Journal of Finance 59, 507-535.

Gompers, P., J. Lerner and D. Scharfstein, 2005, Entrepreneurial Spawning: Public Corporations and the Genesis of New Ventures, 1986 to 1999, Journal of Finance 60, 577-614.

Graham, J.R., Lemmon, M.L., and J.G. Wolf, 2002, Does Corporate Diversification Destroy Value? Journal of Finance 57, 695-720.

Gromb, D. and D. Scharfstein, 20012, Entrepreneurial Activity in Equilibrium, Mimeo, Massachusetts Institute of Technology, Boston.

Hall, P., 1998, Cities in Civilization, Pantheon, New-York.

Hall, M. and L. Weiss, 1967, Firm Size and Profitability, Review of Economics and Statistics 49, 319-331.

Hanson, D., 1982, The New Alchemists: Silicon Valley and the Microelectronics Revolution, Little Brown, Boston.

Hellmann, T., 2007, When Do Employees Become Entrepreneurs?, Management Science 53, 919-933.

Jovanovic, B. and P.L. Rousseau, 2001, Vintage Organization Capital, NBER WP 8166.

Klepper, S., 1996, Entry, Exit, Growth, and Innovation over the Product Life Cycle, American Economic Review 86, 562-583.

Klepper, S., 2002, The Capabilities of New Firms and the Evolution of the US Automobile Industry, Industrial and Corporate Change 11, 645-666.

Klepper, S., 2007, Disagreements, Spinoffs, and the Evolution of Detroit as the Capital of the U.S. Automobile Industry, Management Science 53, 616-631.

Klepper, S. and S. Sleeper, 2005, Entry by Spin-Offs, Management Science 51, 1291-1306.

Klepper, S. and P. Thompson, 2006, Submarkets and the Evolution of Market Structure, Rand Journal of Economics 37, 861-886.

Klepper, S. and P. Thompson, 2009, Disagreements and Intra-industry Spinoffs, mimeo, Carnegie Mellon University and Florida International University.

Klette, T.J. and S. Kortum, 2004, Innovating Firms and Aggregate Innovation, Journal of Political Economy 112, 986-1018.

Lang, L. H. P. and R. M. Stulz, 1995, Tobin's q, Corporate Diversification, and Firm Performance, 
Journal of Political Economy 102, 1248-1280.

Laux, J.M., 1976, In First Gear: The French Automobile Industry to 1914, McGill-Queen's University Press, Montreal.

Loderer, C. and U. Waelchli, 2009, Firm Age and Performance, mimeo, University of Bern.

Loderer, C., K. Neusser, and and U. Waelchli, 2010, Firm Age and Survival, mimeo, University of Bern.

Maksimovic, V. and G. Phillips, 2002, Do Conglomerate Firms Allocate Resources Inefficiently Across Industries? Theory and Evidence, Journal of Finance 57, 721-767.

Matsusaka, J.G., 2001, Corporate Diversification, Value Maximization, and Organizational Capabilities, Journal of Business 74, 409-431.

Matsusaka, J.G. and V. Nanda, 2002, Internal Capital Markets and Corporate Refocusing, Journal of Financial Intermediation 11, 176-211.

Montgomery, C.A., 1994, Corporate Diversification, Journal of Economic Perspectives 8, 163-178.

Penrose, E., 1995, The Theory of the Growth of the Firm, Oxford University Press (First Ed., 1959).

Rajan, R., Servaes, H., and L. Zingales, 2000, The Cost of Diversity: The Diversification Discount and Inefficient Investment, Journal of Finance 55, 35-80.

Roberts, J., 2004, The Modern Firm: Organizational Design and Performance for Growth, Oxford University Press, Oxford.

Rogers, E.M., 1985, The High Technology of Silicon Valley, Institute for Urban Studies Monograph 4, University of Maryland.

Schoar, A., 2002, Effects of Corporate Diversification on Productivity, Journal of Finance 57, 2379-2403.

Sherer, J., 2006, Entrepreneurial Innovation: Evidence From the American Laser Industry, Mimeo, Carnegie Mellon University.

Sutton, J., 1997, Gibrat's Legacy, Journal of Economic Literature 35, 40-59.

Sutton, J., 1998, Technology and Market Structure, MIT Press, Cambridge, MA.

Villalonga, B., 2004, Diversification Discount or Premium? New Evidence From the Business Information Tracking Series, Journal of Finance 59, 475-502.

Wernerfelt, B., 1984, A Resource-Based View of the Firm, Strategic Management Journal 5, 171-180.

Whited, T.M., 2001, Is It Inefficient Investment That Causes the Diversification Discount? Journal of Finance 56, 1667-1691. 

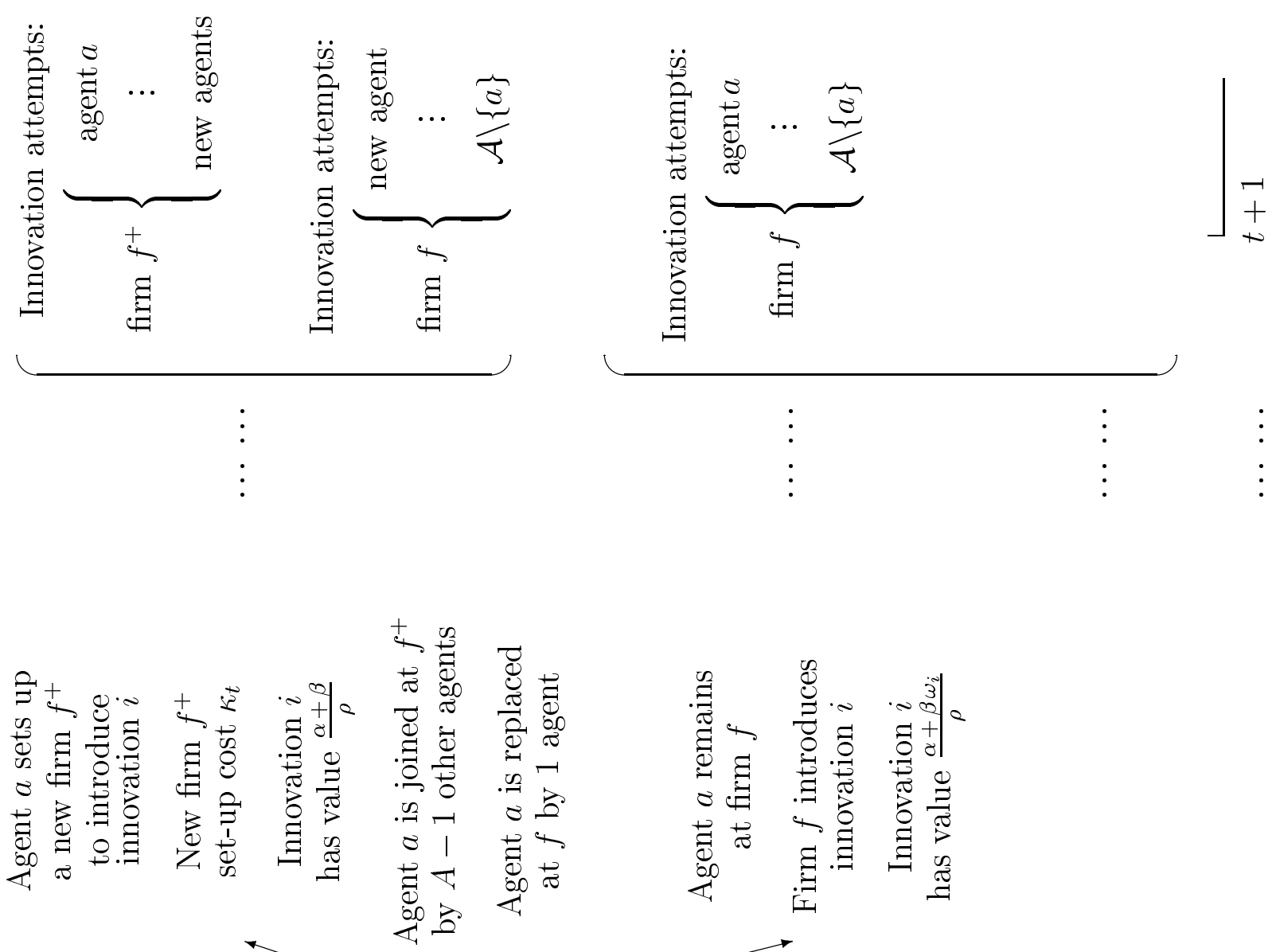

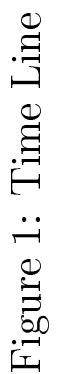
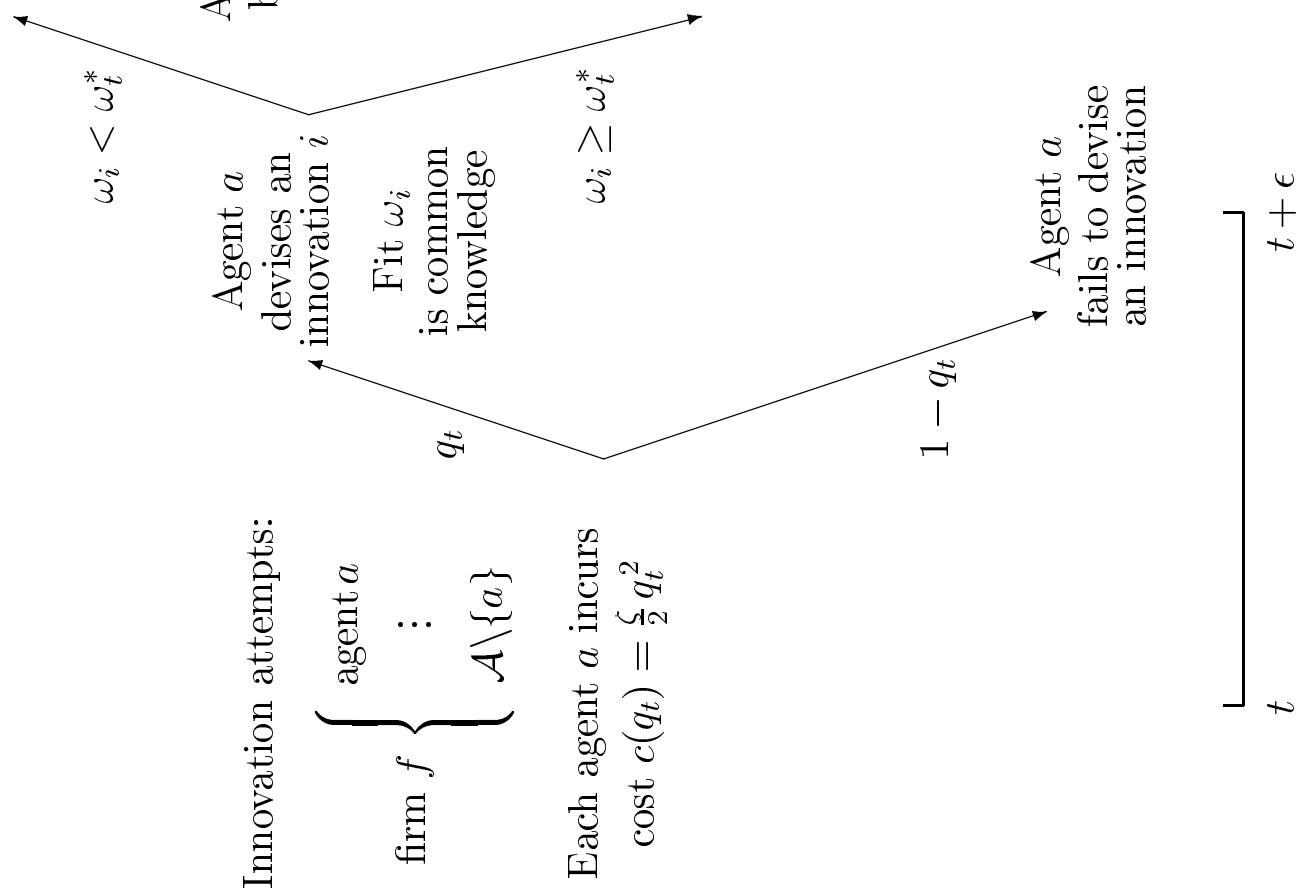


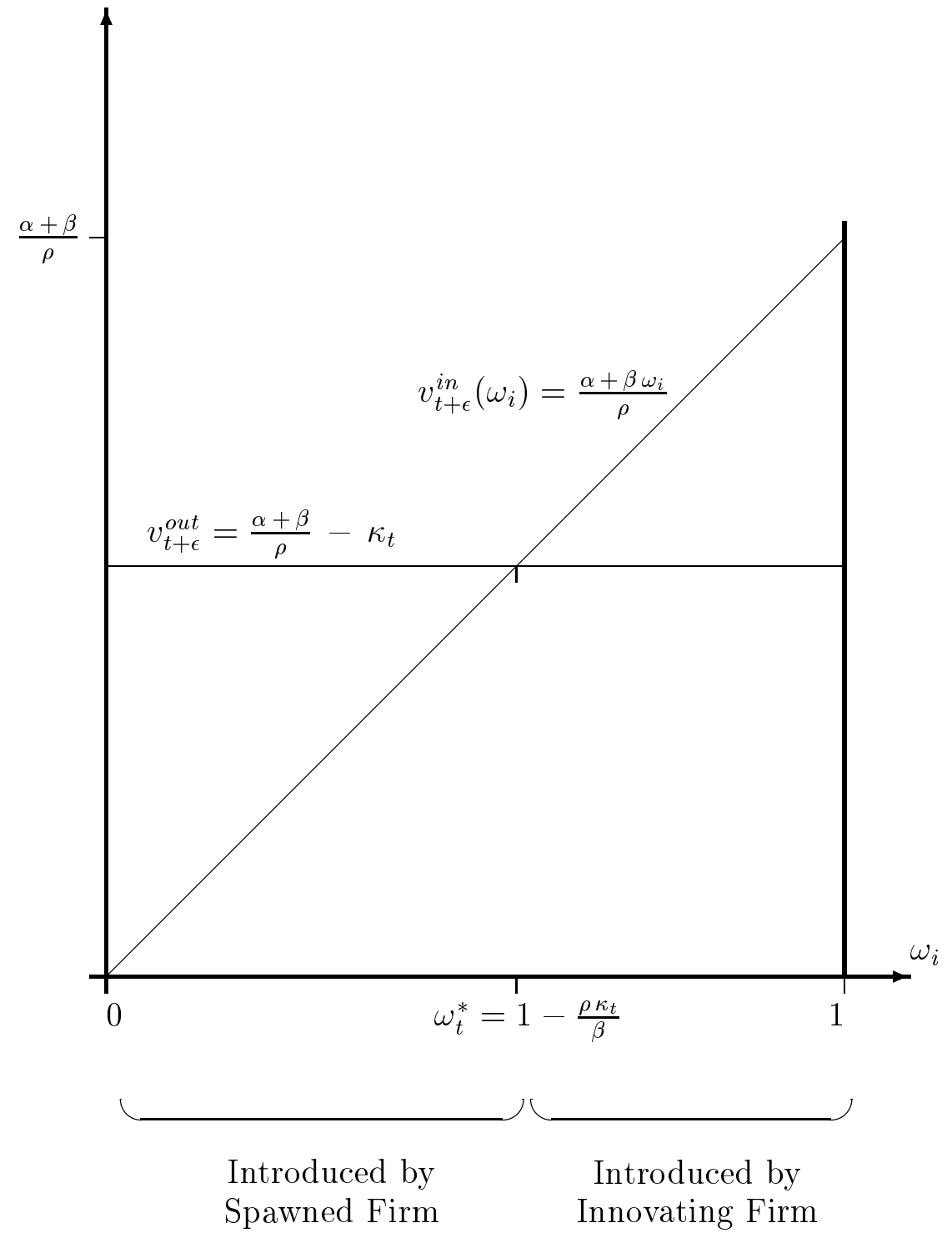

Figure 2: Product Introduction at date $t+\epsilon$ 
Table 1: Comparative Statics

\begin{tabular}{|c||c|c|c|c|c|}
\hline & $\begin{array}{c}\text { Spawning } \\
\text { Frequency } \\
\omega_{t}^{*}\end{array}$ & $\begin{array}{c}\text { Probability } \\
\text { of Innovation }\end{array}$ & $\begin{array}{c}\text { Firm } \\
\text { Size } \\
p_{t}\left[I_{t}\right]\end{array}$ & $\begin{array}{c}\text { Firm } \\
\text { Focus } \\
\mathrm{E}\left[\bar{\omega}_{t}\right]\end{array}$ & $\begin{array}{c}\text { Return on } \\
\text { Assets } \\
\mathrm{E}\left[R O A_{t}\right]\end{array}$ \\
\hline \hline$\alpha$ & 0 & + & + & - & $-/+\dagger$ \\
$\beta$ & + & + & $-^{*}$ & + & + \\
$\kappa_{\tau}$ & - & - & + & - & - \\
$\gamma$ & 0 & + & + & - & - \\
$\rho$ & - & - & - & - & - \\
$\xi$ & 0 & - & - & + & + \\
\hline
\end{tabular}

$*$ if $\alpha / \beta>1 / 4$.

$\dagger \exists \alpha^{*}$ such that - if $\alpha<\alpha^{*}$ and + if $\alpha>\alpha^{*}$. 